\title{
ARTÍCULOS
}

\section{LOS INMIGRANTES ESPAÑOLES EN CONCEPCIÓN (PARAGUAY). ENTRE LA GUERRA GUAZÚ Y LA RECONSTRUCCIÓN NACIONAL (1869-1932).}

\author{
Philip Duncan Webb \\ Universidade de Santiago de Compostela \\ philipduncanwebb@gmail.com
}

Resumen: El presente trabajo analiza el colectivo español en Concepción entre finales de la Guerra de la Triple Alianza y la Guerra del Chaco (1869-1932). La investigación se desarrolla tratando primero la inmediata posguerra (1869-1879), las estrategias de reconstrucción y la llegada de los primeros inmigrantes. Posteriormente, se somete a consideración la consolidación económica que experimentó la villa de Concepción entre 1880 y 1898 así como el papel ejercido por los españoles en este proceso. Finalmente, y tomando también como eje la aportación de la inmigración española, versa sobre la modernización arquitectónica, asociativa, infraestructural y productiva de la ciudad y el interior de la zona de Concepción (actuales Departamentos de Concepción, Amambay y el norte de San Pedro) entre 1899 y 1932.

Palabras clave: Emigración española, inmigración en Paraguay, Concepción, modernización, ganadería, arquitectura, asociacionismo, posguerra.

Tittle: SPANISH IMMIGRANTS IN CONCEPCIÓN (PARAGUAY). BETWEEN THE GUERRA GUAZÚ AND NATIONAL RECONSTRUCTION (1869-1932).

Abstract: This paper analyses the Spanish community in Concepción from the end of the Triple Alliance War to the Chaco War (1869-1932). The immediate post-war period (1869-1879), reconstruction strategies and the arrival of the first immigrants are examined first. The paper then considers the economic development that Concepción experienced between 1880 and 1898 , as well as the role played by Spanish residents in this process. Finally, attention is given to the architectural, associative, infrastructural and productive modernisation of the city and the broader region of Concepción (the modern Departments of Concepción, Amambay and northern San Pedro) between 1899 and 1932, once again with reference to Spanish immigration.

Keywords: Spanish emigration, immigration in Paraguay, Concepción, modernisation, cattle farming, architecture, associationism, post-war.

\section{Introducción a la "capital del norte"}

Los argumentos centrales de este aporte surgieron hace más de cien años en una conversación entre el concepcionero Genaro Romero y el italiano Segundo

Cómo citar este artículo: WEBB, Philip Duncan. Los inmigrantes españoles en Concepción (Paraguay). Entre la Guerra Guazú y la reconstrucción nacional (1869-1932). Naveg@mérica. Revista electrónica editada por la Asociación Española de Americanistas [en línea]. 2020, n. 24. Disponible en: <http://revistas.um.es/navegamerica>. [Consulta: Fecha de consulta]. ISSN 1989-211X. 
Antonioli. Esta conversación quedó plasmada en la monografía El Paraguay progresa: la ciudad de Concepción (1913) del propio Romero, a la sazón jefe de la Oficina de Inmigración y Colonización. Con "escasos recursos y llevando por norma la verdad", Romero editó el libro a base de los "apuntes recogidos en tres días de permanencia en la ciudad en que nací, con el único propósito de presentar á los ojos del inmigrante europeo que llega á nuestra playa, un campo fértil, una tierra de promisión para el trabajo y el capital"1. Acudió a los comercios más acreditados de la ciudad, entre ellos el emporio de Antonioli, donde fue recibido personalmente por el patrón y del que dejó el siguiente testimonio:

\begin{abstract}
"En los trabajos ocúpanse á obreros nacionales, cuya resistencia y facilidad de aprender cualquier oficio, admira el laborioso industrial. [...] Dominado por la curiosidad, me permití preguntar al amable genovés si había llegado al país ya con capitales. Con ese carácter franco que le es tan peculiar me contesta: "Llegué al Paraguay hace 28 años más o menos, sin más recurso que mis brazos, mi honradez y mi salud. En mi bolsillo no tenía más que $\$ 3: 70$ tres pesos con setenta centavos moneda argentina. Trabajé en los primeros tiempos en la construcción de la vía ferrea de Villa Morra en Asunción ganando un peso diario papel [sic], sin comida y durmiendo bajo el techo de un galpón. Nunca, estando sano, me entregaba al dolce far níente, trabajaba en cualquier forma y en cualquier caso. Muchos creen en el exterior que al pisar el Paraguay se encuentra por el suelo libras esterlinas. Se encuentran, sí, pero con el sudor y los brazos; así he conseguido yo después de haber pasado varias peripecias y contratiempos. El Paraguay es un país muy rico pero tiene un gran defecto, una verdadera plaga: sus revoluciones." [...] Tanto él como sus hijos y demás parientes pudiendo vivir en un lujoso palacete, en medio de todos los halagos, son los primeros que se presentan en los talleres y los últimos que se retiran".
\end{abstract}

En las líneas anteriores se atisban los principales temas que se desarrollan en este artículo. Primero, Antonioli empleaba a trabajadores paraguayos. Los inmigrantes constituían un factor económico relevante como generadores de empleo y dinamismo comercial. Por otro lado, el italiano mencionaba las "revoluciones", aludiendo, sin duda, a la sucesión de golpes de Estado y convulsiones militares que habían conmocionado la vida pública desde la Guerra de la Triple Alianza (18641870). Sería una simplificación excesiva atribuir las duras condiciones económicas vigentes durante este período a la inestabilidad de la situación política, pero desde luego sí que representaba uno de los obstáculos que impedían que el Paraguay se convirtiese en un destino de inmigración masiva. Muchos inmigrantes fracasaron. Los que triunfaron, como Segundo Antonioli, siempre fueron una minoría de extranjeros en un país de emigración. En segundo lugar, el inmigrante explicaba que, antes de llegar a Concepción, vivió y trabajó en Asunción. Este hecho pone de manifiesto otro aspecto relevante que se traduce en el hecho de que Concepción era por entonces un destino secundario para los inmigrantes europeos. Al iniciarse el ciclo migratorio, quienes abandonaban sus lugares de origen no se dirigirían directamente a esta ciudad, sino que se asentarían primero en un destino de más fácil acceso y mayor concurrencia migratoria (Asunción, Buenos Aires,

\footnotetext{
${ }^{1}$ ROMERO, Genaro. El Paraguay progresa: la ciudad de Concepción. Asunción: Talleres Gráficos del Estado, 2013, p. 36.

${ }^{2}$ Ibídem, pp. 34-35.
} 
Montevideo...). En tercer lugar, Antonioli afirmaba que no tenía dinero cuando llegó a Asunción, en contraste total con la forma de vida que construiría después. Esto apunta al hecho de que los inmigrantes gozarían, en términos generales, de mayores posibilidades de movilidad social. De hecho, Genaro Romero describe la morada de los Antonioli como un "palacete", de lo que se infiere que, efectivamente, la modernización arquitectónica de la villa concepcionera fue otro de los cambios producidos durante el período estudiado en el que los extranjeros jugaron un papel relevante.

En el presente trabajo, analizamos el colectivo español en Concepción entre finales de la Guerra de la Triple Alianza y la Guerra del Chaco (1932-1935). Si hemos partido del testimonio de Antonioli es porque transmite de modo claro y sencillo una serie de ideas y experiencias que también se observan en las trayectorias de muchos de los inmigrantes españoles. Nuestra contribución se divide en diferentes apartados que arrancan de esta introducción seguida de un resumen del estado de la cuestión que hemos limitado a una revisión de la historiografía producida en los últimos diez años. Posteriormente, se trata el período de la inmediata posguerra de la Triple Alianza (1869-1879) en el que se diseñaron las estrategias de reconstrucción y se produjo la llegada de los primeros inmigrantes. Por su parte, el cuarto apartado trata el desarrollo comercial y económico que experimentó la villa de Concepción entre 1880 y 1898 y el papel ejercido por los españoles en este proceso. Finalmente, el último, que comprende el período entre 1899 y 1932, aborda diferentes aspectos relacionados con la expansión de la ciudad y del interior (actuales departamentos de Concepción, Amambay y el norte de San Pedro), así como los efectos de la modernización asociándolos a la participación de los inmigrantes españoles.
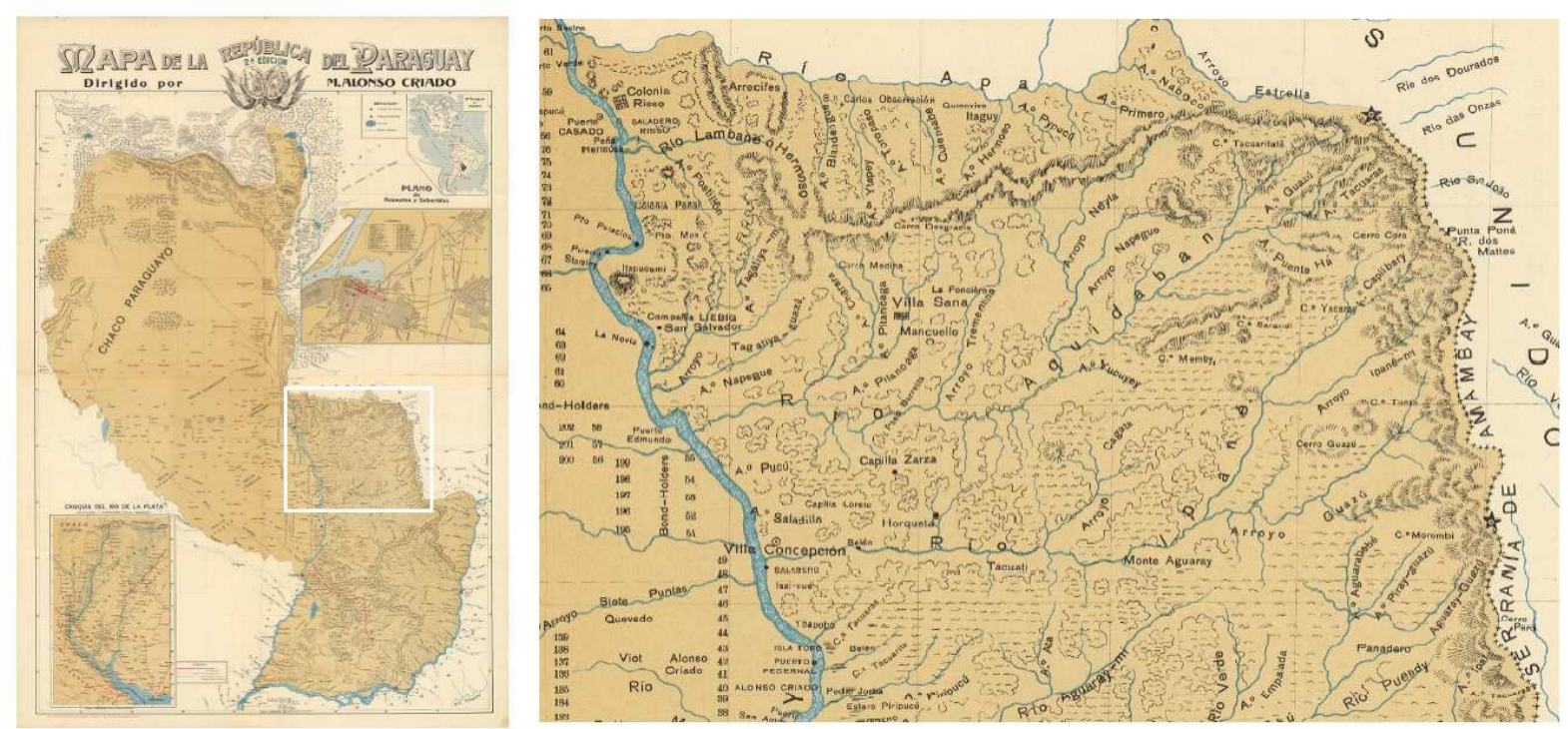

Fig. 1: La zona de Concepción, 1907. Fuente: CAGIAO VILA, Pilar (ed.). Donde la política no alcanza. El reto de diplomáticos, cónsules y agentes culturales en la renovación de las relaciones entre España y América, 1880-1939. Madrid, Iberoamericana, 2018, p. 56. 


\section{Estado de la cuestión}

En los últimos diez años la investigación sobre las migraciones en Paraguay se ha intensificado sensiblemente. Benítez Martínez (2010) ofrece una visión de conjunto de la inmigración europea desde la independencia a partir de un análisis del marco legislativo, los discursos oficiales respecto de la inmigración y la estadística demográfica ${ }^{3}$. Una de las líneas tradicionales dentro de la historiografía paraguaya es el estudio de las colonias agrícolas que se fundaron durante este período bajo protección estatal o empresarial, usualmente pobladas por inmigrantes del Viejo Mundo. Por otro lado, a pesar de la relativamente escasa atención prestada por los historiadores a las migraciones internas y externas de campesinos paraguayos, hay que tener en mente que estos fenómenos siempre fueron cuantitativamente más importantes que la inmigración y han tenido una mayor continuidad en el tiempo (la sangría poblacional puede trazarse casi ininterrumpidamente desde la Guerra de la Triple Alianza). Volviendo al ámbito de la inmigración, la Formación de la familia paraguaya (2011) de Durán Estragó y Romano García constituye todo un hito editorial porque pone a disposición de los investigadores un registro completo de 36 volúmenes de expedientes de soltería, que se conservan el Arzobispado de Asunción, correspondientes al lapso 1776-1939. Por otro lado, en su segundo tomo, esta obra también incluye impedimentos matrimoniales procedentes de la Diócesis de Concepción y Chaco. Estas fuentes albergan una extraordinaria riqueza de datos de carácter personal sobre los inmigrantes que se casaban: nombres, apellidos, edad, país, provincia y a veces parroquia de origen, profesión, nombres de los padres y de los testigos, o la nacionalidad de las personas con que contraían matrimonio ${ }^{4}$.

Respecto de la inmigración, si bien puede afirmarse que Trinacria fue una colonia italiana, San Bernardino una colonia alemana, o Fram una colonia ucraniana, entre las nuevas fundaciones de finales del siglo XIX y principios del XX, o sea en el marco de la inmigración "organizada", nunca hubo una colonia con una mayoría de españoles. La llegada al Paraguay de trabajadores peninsulares fue una manifestación de la inmigración "espontánea" que respondía a las oportunidades existentes en el país de destino, sin mediación directa del Estado o una empresa colonizadora, y en la cual los inmigrantes utilizaban sus propios recursos para viajar y establecerse. Precisamente acerca de algunos de estos inmigrantes, Gamarra Doldán publicó el diccionario biográfico Españoles ilustres en el Paraguay (2011) Además, en la última década se publicaron textos que versan sobre inmigrantes concretos, por ejemplo las Notas sobre la Verdad Autógrafa (2011) de Rodríguez

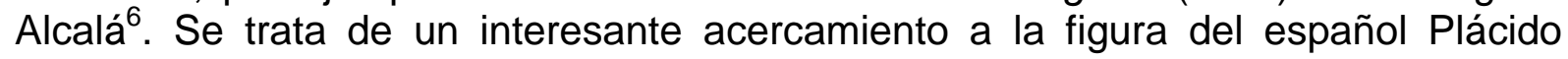
Casaús y las innovaciones técnico-estéticas y discursivas que su trayectoria suponía

\footnotetext{
${ }^{3}$ BENITTEZ MARTíNEZ, María Victoria. Inmigrantes europeos en Paraguay, 1818-1930. En: REY TRISTÁN, Eduardo y CALVO GONZÁLEZ, Patricia. 200 años de Iberoamérica (1810-2010). Actas del XIV Encuentro de Latinoamericanistas Españoles. Santiago de Compostela: Universidade de Santiago de Compostela, 2010, pp. 1099-1121.

${ }^{4}$ DURÁN ESTRAGÓ, Margarita y ROMANO GARCÍA, Martín. Formación de la familia paraguaya. Asunción: Tiempo de Historia, 2011 (2 vols.).

${ }_{5}^{5}$ GAMARRA DOLDÁN, Pedro. Españoles ilustres en el Paraguay. Asunción: Prisa Ediciones, 2011.

${ }^{6}$ RODRíGUEZ ALCALÁ, Javier. Notas sobre La Verdad Autógrafa de Plácido Casaús. De la imagen del poder al poder de las imágenes. Asunción: Ediciones Cabildo Bicentenario, 2011.
} 
para la prensa paraguaya de los años 1880-1890. Una de las investigaciones más extensas en este campo es la tesis doctoral de Morales Raya (2015) que aborda la comunidad catalana en Asunción desde 1870 hasta 1932 ${ }^{7}$. A una escala más reducida, cabe citar nuestro artículo del que sigue una línea de enfoque regional similar a la de la investigadora catalana al tratar la inmigración gallega en Asunción durante la época de "entreguerras" $(1870-1932)^{8}$. Una de las principales vertientes de los trabajos mencionados se centra en el empuje que los españoles radicados en Paraguay proporcionaron al comercio finisecular. En lo tocante a las relaciones comerciales hispano-paraguayas, es preciso mencionar los trabajos de Dalla-Corte Caballero y Cagiao Vila sobre instituciones como el Banco de España y Paraguay ${ }^{9}$ o la Casa de América de Barcelona ${ }^{10}$.

En el caso que nos ocupa, nos interesamos por uno de los aspectos menos estudiados de la inmigración en Paraguay. Poco se sabe todavía de la inmigración espontánea fuera de Asunción. Gómez Vázquez realizó un ejercicio de rescate de memoria histórica que reproduce documentos inéditos y fotografías pertenecientes al Centro Español de Villarrica ${ }^{11}$. No obstante, es preciso incorporar estos datos a un acercamiento sistemático a la inmigración en la zona guaireña que relacione el objeto de estudio con el contexto histórico más amplio. Por otro lado, existen otras contribuciones anteriores relacionadas con otras ciudades. Así, el asunto de la inmigración ya figuraba, entre otros temas, en los trabajos de Alvarenga Caballero sobre Concepción ${ }^{12}$-de gran provecho para nuestra investigación- y de Boccia Romañach sobre Pilar de Ñeembucú ${ }^{13}$. Por último, cabe destacar, como estudio acerca de una colectividad concreta, la monografía Tierra, trabajo y religión (2002) de Zub Kurylowicz que trata la inmigración eslava en las Misiones e Itapúa ${ }^{14}$.

\section{Concepción y la primera posguerra (1869-1879)}

En términos (muy) relativos, los estragos de la "Guerra Guazú" en Concepción no fueron tan insoportables como en el resto de la República. Hasta poco antes de su ocupación por el ejército brasileño, el 18 de octubre 1869, Concepción seguía

\footnotetext{
${ }^{7}$ MORALES RAYA, Eva. La emigración catalana a Paraguay entre finales del siglo XIX y principios del XX: sociedad, cultura, política [tesis doctoral inédita]. Universitat de Barcelona, 2015.

${ }^{8}$ WEBB, Philip Duncan. "Armados de noble ambición": os galegos en Paraguai e o seu lugar no ámbito asociativo español (1870-1932). Murguía: Revista Galega de Historia. 2016, n. 34, pp. 17-36.

${ }^{9}$ DALLA-CORTE CABALLERO, Gabriela. Relaciones hispano-paraguayas durante la Primera Guerra Mundial: el "Banco de España y Paraguay" en Asunción. Anuario de Estudios Americanos. 2016, n. 73, pp. 261-290.

10 CAGIAO VILA, Pilar y DALLA-CORTE, Gabriela. La Casa de América de Barcelona y sus relaciones con Paraguay: comercio y diplomacia (1912-1922). En: NAVARRO, Consuelo y PRADO, Gustavo H. (coords.). Intellectualism and Migration: International Networks of European Culture (XIXXXI). Rockville: GlobalSouth Press, 2016.

${ }^{11}$ GÓMEZ VÁZQUEZ, Melanio. Centro Español de Villarrica en el año de su centenario. Villarrica: Editorial Villa Rica, 2015.

${ }^{12}$ ALVARENGA CABALlERO, Pedro A. Villa Real de Concepción en los días de la ocupación brasileña. Historia Paraguaya. 1999, n. 39, pp. 49-94.

${ }^{13}$ BOCCIA ROMAÑACH, Alfredo. La Villa de Pilar de Neembucú en la historiografía paraguaya desde su fundación hasta mediados del siglo XX. Asunción: Servilibro, 2007.

${ }_{14}$ ZUB KURYLOWICZ, Roberto. Tierra, trabajo y religión. Memoria de los inmigrantes eslavos en el Paraguay. Asunción: El Lector, 2002.
} 
siendo la reserva pecuaria para el sustento de las fuerzas paraguayas ${ }^{15}$. Su alejamiento de las operaciones bélicas hasta el último año de la guerra, sin duda, ayudó a que la posterior recuperación fuese más rápida que en otras regiones. Sin embargo, mientras el mariscal Francisco Solano López iba por los caminos que lo llevarían al fatídico paraje de Cerro Corá, donde moriría el 1 de marzo 1870, la guerra se prolongaba y la sociedad concepcionera comenzó a sufrir las mismas privaciones que sus compatriotas del sur. Los comerciantes de la Villa cerraron sus negocios. Esta pequeña burguesía era mayoritariamente concepcionera o asuncena, pero también había un puñado de extranjeros: un chileno, un correntino, dos portugueses y un español, Gaspar Rodríguez, "natural de Galicia y vecino de Villa Concepción"16, lo que sugiere que la inmigración urbana contaba con ciertos antecedentes en la ciudad que se remontaban a la presidencia de Carlos Antonio López (1844-1862).

Además de la desaparición del comercio, otro factor que moldearía las relaciones socio-económicas de la posguerra era la parcial destrucción de la élite concepcionera a manos de militares paraguayos, particularmente del sargento mayor Gregorio Benítez ("Tóro Pychãi” o el 'toro piquento'). Circulaba la creencia de que esas familias patricias habían sido cómplices en las supuestas conspiraciones de Benigno López Carrillo -fusilado el 21 de diciembre 1868- contra su hermano el mariscal ${ }^{17}$. Las represalias culminaron en la masacre producida el 3 de mayo 1869 en la localidad vecina de Horqueta, donde fueron lanceadas más de treinta mujeres procedentes de aquellas familias, entre ellas varias menores de edad ${ }^{18}$. Entre finales de 1869 y 1870, los comandantes brasileños, José Antônio Correia da Câmara y Gaston d'Orléans, Conde d'Eu, preferían recorrer el norte ocupando distintas plazas en vez de arriesgarse a un encuentro frontal con López, y, según Alvarenga Caballero, los "vivanderos" que abastecían a los ejércitos retrasaban adrede la llegada de víveres para alargar el conflicto y maximizar sus beneficios ${ }^{19}$. Lo cierto es que había vivanderos que amasaron verdaderas fortunas. Según dejó escrito el pontevedrés Francisco Javier Brabo (o Bravo), que proveía a los brasileños durante la campaña de Corrientes (1865), aunque decidió non acompañarlos más allá de Paso de los Libres:

"Continuaron algun tiempo mis socios ganando triple que yo, pero no por eso fueron más felices, cabiéndome á mí la satisfacción de haber contribuido, impulsado tan sólo por la gratitud á los servicios que me prestaron en otro tiempo, á que el uno de ellos se embolsase un millon de duros, y el otro medio próximamente ${ }^{20,}$.

\footnotetext{
${ }^{15}$ Alvarenga CABallero, Pedro A. Villa Real de Concepción... Op. cit., p. 59.

${ }^{16}$ Ibídem, p. 54.

${ }^{17}$ ARECES, Nidia R. Terror y violencia durante la Guerra del Paraguay: "La masacre de 1869" y las familias de Concepción. Revista Europea de Estudios Latinoamericanos y del Caribe. 2006, n. 81, p. 53.

${ }^{18}$ ALVARENGA CABALLERO, Pedro A. Villa Real de Concepción... Op. cit., pp. 66-67.

${ }^{19}$ Ibídem, p. 69.

${ }^{20}$ BRABO, Francisco Javier. Coleccion de documentos relativos á la expulsión de los Jesuitas de la República Argentina y del Paraguay, en el reinado de Cárlos III. Madrid: Est. Tip. De J.M. Pérez, 1872, p. 48.
} 
Desde finales del siglo XVIII, el proceso colonizador en Concepción había consistido en la creación de un sistema de estancias ganaderas o yerbateras que funcionaban como puntos de defensa contra los indígenas y los portugueses/brasileños del Mato Grosso. Los pobladores que se trasladaban a las estancias eran campesinos paraguayos -migrantes espontáneos- que prestaban sus servicios a cambio de seguridad ${ }^{21}$. Algunos establecimientos eran privados, pero la mayoría eran estancias como "La Patria", de propiedad pública, destinadas a proveer al ejército y producir alimentos para distribuir entre los pobres. La guerra demolió este sistema. Anteriormente, el fuerte de Bella Vista sobre el río Apa había sido el núcleo de una estancia "La Patria" que contaba con tres leguas (5.625 hectáreas) de pastoreo ${ }^{22}$. Cuando el geógrafo escocés Keith Johnston visitó el lugar en 1874 con la Comisión de Límites, pudo observar que sus "barracas ennegrecidas [...] están casi cubiertas de vegetación"23. Con la liquidación de la infraestructura militar paraguaya, los pueblos que habían gozado de cierta seguridad detrás de la frontera estanciera estaban expuestos a los ataques de los brasileños y de los indios mbayás. En uno de sus malones, los mbayás saquearon la "Villa de pardos y mulatos" San Salvador de Tevegó, al norte del río Aquidabán, y los pobladores tuvieron que huir a Belén ${ }^{24}$.

La campaña del norte terminó cuando el ejército imperial derrotó al comandante Cañete en el combate de Sanguina. Solo faltaba perseguir a López rumbo a Cerro Corá. Mientras tanto, los caminos hacia Concepción se llenaban de "mulheres magras e macilentas, com os traços da belleza quase apagados, cobertas de andrajos" y "meninos nús amarellos, barrigudos, com as costellinhas á mostra" ${ }^{25}$. Se trataba de familias concepcioneras que regresaban a casa y de refugiados procedentes de pueblos que ya no eran habitables. Acerca de ese momento, Alvarenga Caballero escribió que:

"[...] al llegar a la Villa luego de subir las altas lomas de Itacurubí y la situada al noreste, encontraron el antiguo paraíso de sus amores y sus sueños, el edén de sus recuerdos más preciados, con las casas ocultas por la "maciega". La antigua plaza mayor o de armas, convertida en bosque enmarañado, y los alrededores convertidos en junglas en donde rugían los yaguaretés y los pumas ${ }^{26 "}$.

Sin embargo, en poco tiempo la gente empezó a pulular por las calles. Más allá de los concepcioneros nativos y los refugiados estaban los soldados brasileños, principalmente "kamba" (negros) riograndenses, y con ellos vivanderos, comerciantes, traficantes y buscadores de "pláta yvyguy" (dinero, joyas y otros tesoros ocultados durante la guerra). Con el ejército llegaron mujeres brasileñas,

\footnotetext{
${ }^{21}$ ARECES, Nidia R. La política de tierras en Concepción, frontera norte paraguaya, durante el gobierno de Carlos A. López. Prohistoria. 1998, n. 2, pp. 93-94.

${ }^{22}$ Ibídem, p. 99.

${ }^{23}$ JOHNSTON, Keith. Recent Journeys in Paraguay. The Geographical Magazine. 1875, 2.9-11, p. 271.

${ }^{24}$ ALVARENGA CABALLERO, Pedro A. Villa Real de Concepción... Op. cit., p. 71.

${ }^{25}$ POTTHAST, Barbara. Niños soldados y niñas famélicas. En: POTTHAST, Barbara y CARRERAS, Sandra (eds.). Entre la familia, la sociedad y el Estado. Niños y jóvenes en América Latina (siglos $X I X-X X)$. Madrid: Iberoamericana Editorial Verveurt, pp. 108-109.

${ }^{26}$ ALVARENGA CABALLERO, Pedro A. Villa Real de Concepción... Op. cit., p. 73.
} 
argentinas y uruguayas que ejercían la prostitución sobre la "calle Corta" frente al río Paraguay $^{27}$, aunque podemos suponer que también habría mujeres que cocinaban para los militares, lavaban ropa y realizaban otros quehaceres cotidianos en los campamentos y cuarteles, donde la presencia femenina no era nada insólita en el siglo $\mathrm{XIX}^{28}$. Muchos de estos hombres y mujeres se quedaron y, de algún modo, la guerra los convirtió en los primeros inmigrantes.

El colapso del comercio y la desaparición de una parte de la élite tradicional creó oportunidades para la consolidación socio-profesional de los recién llegados. En el contexto del "virtual protectorado" de la ocupación aliada ${ }^{29}$, los oficiales y los proveedores de los ejércitos fueron los primeros en establecerse. Por ejemplo, el militar brasileño Hugo Heyn residió a lo largo de la década de los setenta en Concepción. En 1878 trabajaba en la casa de ex proveedor Tomás Larangeira justo en el momento en el que este comenzó a explotar los yerbales naturales de la región ${ }^{30}$. Sobre ambos personajes volveremos más adelante. Por su parte, los inmigrantes italianos también se adelantaron en el tiempo a otras nacionalidades. De hecho, En 1874, Keith Johnston describía la "monotonía somnolienta" que caracterizaba la Villa, privada como estaba del gran comercio yerbatero de otrora, declarando que "los que trabajan en este lugar son casi todos italianos" ${ }^{31}$.

Hay múltiples factores que pueden explicar el predominio comercial de los inmigrantes en Concepción. Uno tiene que ver con la capacidad de inversión de la que carecían los paraguayos para poder competir con ellos. Pero, además, las desigualdades de género debieron tener también una influencia importante. En términos generales, en 1870, entre los supervivientes de la Guerra Guazú quedaba un promedio de cuatro mujeres por cada varón ${ }^{32}$. El desajuste demográfico era menos drástico en Concepción y según Johnston, en 1874, 400 mujeres y 200 hombres habitaban la Villa, repartidos en 150 viviendas $^{33}$. Entonces, por esos años eran las mujeres paraguayas las que se encargaban de casi toda la producción agrícola del país ${ }^{34}$. Todo ello favoreció que los inmigrantes creasen toda una gama de industrias y artesanías durante la posguerra.

Si partimos del primer registro de los negocios existentes en la Villa que hemos podido consultar publicado en El comercio paraguayo en $1898^{35}$, se desprende que, a esa altura, los inmigrantes llegados hasta entonces ocupaban nichos laborales según su nacionalidad. Pero, de acuerdo con Alvarenga Caballero, este proceso de especialización ya se había iniciado en la década de 1870:

\footnotetext{
27 Ibídem, pp. 74-75, 78.

${ }^{28}$ POTTHAST, Barbara. Niños soldados... Op. cit., p. 91.

29 JOHNSTON, Keith. Recent Journeys in Paraguay. Op. cit., p. 265.

${ }^{30}$ El comercio paraguayo. 1898. (¿Asunción: Talleres Nacionales de H. Kraus?), p. 146.

31 JOHNSTON, Keith. Recent Journeys in Paraguay. Op. cit., p. 271.

32 DALLA-CORTE CABALLERO, Gabriela. Mujeres, economía y sociedad de la República del Paraguay. Anuario de Historia. 2018, n. 30, p. 196.

33 JOHNSTON, Keith. Recent Journeys in Paraguay. Op. cit., p. 271.

${ }^{34}$ DALLA-CORTE CABALLERO, Gabriela. Mujeres, economía... Op. cit., p. 213.

${ }^{35}$ El comercio paraguayo. Op. cit., pp. 627-631.
} 
"El ejército brasileño era uno de los compradores asiduos de las carpas y barracas, y pronto se comenzaron a construir locales especiales para negocios, tiendas diversas, hoteles. Los italianos, laboriosos, abrían locales de toda laya: confiterías, verdulerías, ferreterías, y más tarde, baldoserías, licorerías, panaderías, fábricas de hielo y los españoles, de Cataluña especialmente, se especializaban en curtiduría, grandes talleres, herrerías y florecieron las bellas artes, con apertura de clases de música, pintura, danzas, teatro, etcétera ${ }^{36 " .}$

La explícita alusión a los españoles, particularmente a los catalanes, invita a preguntarse si también había en la Villa inmigrantes procedentes de otras regiones peninsulares. Sin embargo, en cuanto a la existencia fuentes que permitan corroborarlo, es necesario señalar que los años setenta en Concepción constituyen una especie de "edad oscura" de la que sobreviven muy pocos documentos oficiales. A ello se añade que la industria editorial no arrancó realmente hasta finales del siglo XIX y que la prensa, de la que no tenemos noticias hasta 1892 cuando aparece el que debió ser el primer periódico local (El Eco de la Campaña), no rinde demasiada información sobre la Villa. Por este motivo, solo hemos podido identificar los nombres de dos españoles que se mudaron a Concepción entre 1869 y 1879.

El primero es Guillermo Ocariz, plausiblemente de origen vasco, navarro o riojano (aparte de ser un apellido común en esas regiones, nos consta que su hija Teresa se casó con José Bañuelos ${ }^{37}$, quien por su parte era del Villar de Arnedo, cerca de Logroño ${ }^{38}$ ). Ocariz nació en 1850 o 1851, llegó al Paraguay en 1869 y trabajó durante dos años en la casa de Nicolás Otaño, un oriental que formaba parte de la cohorte de ciudadanos de los países aliados que se establecieron en Concepción durante la primera posguerra ${ }^{39}$.

El segundo es el gallego Victoriano Abente y Lago, nacido en la década de 1840 en Muxía (A Coruña). Su hermano Victorino, autor de poemas como La Sibila paraguaya (1886) o Salto del Guairá (1891) que dejaron una profunda huella en la historia de las letras paraguayas, estaba empleado en la proveeduría argentina cuando arribó a Asunción en $1869^{40}$. Victoriano lo siguió poco después. No se sabe en qué año se trasladó a Concepción, pero la familia residía allí en 1879 cuando nació su hijo Luis Abente Haedo, el futuro Cónsul-General del Paraguay en Montevideo ${ }^{41}$. Más tarde, los Abente se mudaron en distintos momentos desde Concepción a la capital, donde fijaron su residencia en la calle Villarrica $86^{42}$. En Asunción, Victoriano mantendría estrechos vínculos con la colectividad española. De hecho, cuando el 27 de julio 1903 el asturiano Rafael Calzada, en su condición de representante de la Liga Republicana Española en Argentina, convocó una reunión

\footnotetext{
${ }^{36}$ ALVARENGA CABAllero, Pedro A. Villa Real de Concepción... Op. cit., p. 89.

37 Casa de la Cultura "Carlos Colombino", Concepción (en adelante: CCCC). Telegrama de José Bañuelos a Gaspar Ocariz y Cía., 30 de septiembre 1930.

${ }^{38}$ CCCC. Carta de Gerardo Bañuelos a José Bañuelos, 9 de septiembre 1909.

39 MONTE DOMECQ, Ramón. La República del Paraguay en su primer centenario, 1811-1911. Buenos Aires: Compañía Sudamericana de Billetes de Banco, 1911, p. 351.

${ }^{40}$ ABENTE Y LAGO, Victorino. Antología poética, 1867-1926. Recopilación de Cándido Samaniego Abente. Asunción: Editora Litocolor, 1984, p. 5.

${ }^{41}$ CENTURIÓN, Carlos R. Historia de las letras paraguayas. Vol. II. Buenos Aires: Editorial Asunción, 1948 (3 vols.), p. 215.

${ }^{42}$ BERAUD, Carlos. Guía comercial e industrial del Paraguay. Asunción: Carlos Beraud, 1904, p. 202.
} 
para fundar un Partido Republicano Español en Asunción, Victoriano Abente figuró desde primera hora como vocal del jurado del comité central constituido a tal efecto junto a Andrés Luces, a quien volveremos a mencionar, el comerciante catalán Miguel Prats y el gallego Ricardo Faraldo. Por su parte, su hermano Victorino fue elegido vicepresidente segundo del comité; el primero sería el médico catalán Flaviano García Rubio mientras que el economista vasco Ramón de Olascoaga fue elegido como presidente ${ }^{43}$.

A pesar de lo dicho con anterioridad, ni Guillermo Ocariz, ni Victoriano Abente parecen haber trabajado en los sectores comerciales que señalan Romero y Alvarenga. Sus fortunas, como veremos, se hicieron en el sector ganadero.

\section{Concepción "la opulenta" (1880-1898)}

Si los primeros lustros de la posguerra continúan siendo por el momento un período bastante opaco, de la década siguiente hemos podido obtener datos más nítidos que arrojan luz sobre la evolución de la Villa y las circunstancias referidas a los inmigrantes.

En 1880, Rosendo Carísimo y Tomás Larangeira, a quien ya hemos mencionado con anterioridad, obtuvieron permiso para usufructuar un nuevo muelle en el puerto de Concepción ${ }^{44}$. Así se sumaba la creciente influencia del inmigrante brasileño con el poderío tradicional de Carísimo, un caudillo que llevaba el apodo cariñoso de "Karichu" ("mosquetita amarilla", un tipo de pájaro), en parte porque no había participado en la masacre de $1869^{45}$. Es un dato en cierto sentido simbólico porque 1880 es el año en que Concepción comienza a llamarse "la opulenta"46. Este título tiene que entenderse en el marco de la precariedad que se vivía el resto del país. Que fuese muy difícil recuperarse de los destrozos materiales y demográficos de una de las guerras más sangrientas de la historia americana no es extraño. Era inevitable. Pero, además, existían otros factores que ralentizaban el proceso y que estaban estrechamente ligados con la situación política. Tras los gobiernos de José Gaspar Rodríguez de Francia (1814-1840) y los López, padre e hijo, que se palmaron en regímenes fuertes y hegemónicos, la Guerra de la Triple Alianza fragmentó el poder político en distintas facciones. Los opositores a los gobiernos anteriores regresaron al país para disputar la arena política con los ex comandantes de López: caudillos como Cándido Bareiro, Patricio Escobar, Bernardino Caballero, o Gregorio Benítez, el "Tóro Pychãi”"47.

Esta situación desembocó en un alto nivel de inestabilidad y violencia política. Por otro lado, los préstamos de Londres de 1871-1872 podrían haber sido una buena oportunidad para revitalizar la tesorería del Estado, pero por culpa del masivo desfalco cometido por algunos intereses paraguayos, y lo que equivalía a una estafa por parte de los corredores británicos, produjeron el efecto de hundir el crédito

\footnotetext{
${ }^{43}$ El Liberal (Madrid). 13 de agosto 1903, p. 2.

${ }^{44}$ CCCC. "Datos sobre Concepción", informe inédito de Pedro A. Alvarenga Caballero, 1985.

${ }^{45}$ ALVARENGA CABALLERO, Pedro A. Villa Real de Concepción... Op. cit., p. 82.

${ }^{46}$ Ibídem, p. 91.

${ }^{47}$ RODRÍGUEZ ALCALÁ, Javier. Notas sobre La Verdad Autógrafa... Op. cit., p. 5.
} 
nacional y endeudar el país durante décadas ${ }^{48}$. Con todo, la década de los ochenta representa la concreción de cierta solidez económica y un mínimo nivel de estabilidad bajo el gobierno de Bernardino Caballero (1880-1886).

Fue precisamente durante esa etapa cuando se fundó en Concepción una de las primeras empresas españolas que podemos denominar como tal. Se trataba de "La Concepcionera", un negocio de zapatería y talabartería que fue creciendo al compás de la mejora económica de esos años. Creada en 1885 por el inmigrante Francisco Closa, una década más tarde, al asociarse este con Benjamín Colunga ${ }^{49}$, giraría bajo la firma "Closa y Colunga". Poco después, en 1898, según El Comercio Paraguayo era la única talabartería de la Villa ${ }^{50}$. Y aunque no disponemos de datos acerca de los primeros años del negocio -las "peripecias y contratiempos" a las que se refería Segundo Antonioli- sí sabemos que cuando los comerciantes querían ser incluidos en los álbumes gráficos y guías ilustradas que se publicaron durante las primeras décadas del siglo XX tenían que aportar dinero ${ }^{51}$. Así, si un empresario como Francisco Closa figuraba, por ejemplo, en el álbum del primer centenario de Monte Domecq, es porque ya había llegado a ser 'alguien'. Y según este publicista, en 1911, "La Concepcionera", establecida sobre la calle Brasil esquina Pedro Juan Caballero, era "por su inmejorable surtido [...] una de las más importantes de la plaza. Posee una bien montada curtiembre, y su capital en giro es de más de doscientos mil pesos de curso legal" ${ }^{\prime 52}$. Como otros comerciantes al nivel nacional, Closa se benefició de la paz política reinante bajo el presidente Eduardo Schaerer (1912-1916) y el auge exportador que hubo durante la Primera Guerra Mundial ${ }^{53}$, ya que en 1915 su capital alcanzaba "más de \$300.000 c/l". Cecilio Báez, quien proporciona esa cifra, explica que los talleres de Francisco y su hijo Alberto Closa "están montados modernamente y en ellos trabajan un buen número de operarios todos nacionales. Sus compras las efectúa en las principales fábricas Yanquis y Europeas" $"$.

En la anterior cita destacan dos elementos relativos a la "función" de los inmigrantes como agentes de penetración capitalista en una sociedad cuya base económica aún consistía en relaciones precapitalistas de subsistencia ${ }^{55}$. Al tener sus talleres "montados modernamente" y comprar de las "fábricas Yanquis y Europeas", Closa aportaba su grano de arena al proceso por el cual las nuevas tecnologías y productos de la Revolución Industrial se insertaban en el mercado paraguayo. Por otro lado, "La Concepcionera" también llegó a ser una fuente de empleo para un "buen número de operarios todos nacionales". La creación de este proletariado paraguayo era un fenómeno reciente, fruto de los grandes cambios que se iban

\footnotetext{
${ }^{48}$ CABALLERO CAMPOS, Herib. Historia de las relaciones entre Paraguay y Gran Bretaña del siglo XVIII al siglo XXI. Asunción: Servilibro, 2017, pp. 95-97.

${ }^{49}$ MONTE DOMECQ, Ramón. La República del Paraguay... Op. cit., p. 337.

${ }^{50}$ El comercio paraguayo. Op. cit., p. 631.

${ }^{51}$ ALVARENGA CABALLERO, Pedro A. Villa Real de Concepción... Op. cit., 39, p. 83.

${ }^{52}$ MONTE DOMECQ, Ramón. La República del Paraguay... Op. cit., p. 337.

${ }^{53}$ CAGIAO VILA, Pilar y DALLA-CORTE, Gabriela. La Casa de América de Barcelona... Op. cit., pp. 10-11.

${ }^{54}$ BÁEZ, Cecilio. El Paraguay moderno. Asunción: Talleres Nacionales de H. Kraus, 1915, p. 357.

55 TONESS, Odin Alf. The Political and Social History of a Paraguayan Town [tesis doctoral]. University of Illinois, 1973, p. 63.
} 
produciendo en el mundo rural desde mediados de los años ochenta.

A este respecto, en 1882, Benigno Teijeiro Martínez, exiliado republicano de origen gallego y Cónsul del Paraguay en Concepción del Uruguay (Entre Ríos), opinaba acerca de lo que para él era uno de los problemas más acuciantes para la modernización del país al que representaba: "el agricultor paraguayo se limita a plantar una cantidad muy reducida, y cada año siembra exactamente igual al anterior. Con este sistema no es posible concebir progreso alguno" ${ }^{\prime 56}$. En parte, lo que criticaba era la inexistencia de una "mentalidad emprendedora" o "cultura del capitalismo" en el agro paraguayo. Para remediar esta situación, el gobierno pretendía estimular la inmigración europea porque, en palabras de José Segundo Decoud, "la fisonomía moral de un pueblo no es tan fácil cambiarla. Era necesario que el elemento extranjero estuviera en mayor número para que pudiera operar el fenómeno de la transformación" ${ }^{, 57}$.

Además de lo señalado por Decoud, otro obstáculo para la formación de una industria agropecuaria privada era el hecho de que casi la totalidad de la tierra pertenecía al fisco ${ }^{58}$. Por este motivo, en 1886, Caballero tomó una de las medidas económicas más rupturistas de la historia paraguaya al licitar las primeras subastas de vastas extensiones de estos terrenos. Uno de los resultados de la venta de tierras fiscales fue la repentina concentración de recursos en manos de unos pocos y la expulsión de miles de campesinos de sus parcelas ancestrales. En Concepción, a partir de 1886, fueron dos las empresas yerbateras que se adueñaron de la mayor parte del territorio. Una era la Industrial Paraguaya S.A. que llegó a acumular unas 2.647.727 hectáreas, de las cuales 855.000 eran yerbales $^{59}$. Esta empresa se había fundado el 28 de abril 1887 y uno de sus accionistas era el mismísimo Bernardino Caballero $^{60}$. La otra empresa era brasileña. Ya mencionamos que en 1878 el brasileño Hugo Heyn trabajaba en la casa de Tomás Larangeira, cuando este empezó a faenar los yerbales del norte. Veinte años después, encontramos a Heyn como superintendente general de la representación asuncena de la poderosa Companhia Matte Larangeira que poseía fábricas en Rio de Janeiro y Buenos Aires, 14.000 carretas, 700 bueyes y más de 3.000 peones $^{61}$.

Otro de los empleados de la Matte Larangeira, desde el año 1893, era el español Andrés Luces. Luces, "persona bastante conocida entre nosotros por sus méritos individuales, laboriosidad y honradez", gerenciaba sus actividades en la zona Sud Yerbatera sobre el río Aguaray-mí en la región de Concepción ${ }^{62}$. Como veremos, unos años después actuaría como vocal del jurado del Partido Republicano Español junto a Victoriano Abente y Lago. Y desde luego, no parece una casualidad habida cuenta que el empleador de Luces era amigo de los Abente. Fernando Abente

\footnotetext{
${ }^{56}$ TEIJEIRO MARTíNEZ, Benigno. El Paraguay: memoria bajo el punto de vista industrial y comercial en relación con los países del Plata. Buenos Aires: Establecemiento Tipográfico Calle de Perú no 107, 1882, p. 22.

${ }^{57}$ Citado en TEIJEIRO MARTíNEZ, Benigno. El Paraguay... Op. cit., p. 25.

${ }^{58}$ ARECES, Nidia R. La política de tierras en Concepción... Op. cit., p. 98.

${ }^{59}$ Ibídem, p. 99.

${ }^{60}$ El comercio paraguayo. Op. cit., pp. 115-117.

${ }^{61}$ Ibídem, pp. 140-146.

${ }^{62}$ lbídem, p. 147.
} 
Haedo, hijo de Victoriano, colaboraba en las tareas productivas de la Matte Larangeira $^{63}$. Prueba de ello es que cuando su hermano Víctor, futuro presidente de la Cámara de Diputados, redactó su tesis doctoral en 1903, escribió en ella como dedicatoria: "A mi padrino, el comendado Don Thomaz Larangeira en testimonio de cariño y gratitud" 64 .

De acuerdo con la primera memoria anual de la Matte Larangeira, presentada por su presidente Francisco Murtinho en Rio de Janeiro, el 27 de mayo 1893:

"Fué en 1878 cuando el ciudadano señor Tomás Larangeira, rompiendo con el espíritu atrasado de aquella época, caracterizado por el desánimo y la falta de iniciativa para los trabajos industriales, acometió valerosamente la explotación de aquellos yerbales, lleno de confianza en el éxito de tan temeraria empresa"65.

La velada crítica que efectuaba el doctor Murtinho acerca de la mentalidad precapitalista del campesino paraguayo recuerda a la sentencia emitida por Benigno Teijeiro Martínez. Pero, al margen de ello, no cabe duda de que su relato pecaba de ciertas exageraciones pues Tomás Larangeira no era el único que veía el potencial de la yerba mate concepcionera. Ya indicamos que en la primera posguerra Guillermo Ocariz trabajaba en los yerbales, "que en aquella época pertenecían al fisco. Allí trabajó subalternamente, siendo sus patrones los señores Juan Navarro, Nicolás Otaño y Sebastián Durán"66. Sin embargo, lo que sí parece cierto es que Larangeira consiguió aprovechar este recurso natural con más éxito que nadie.

La desposesión de los campesinos y su transformación en clase asalariada produjo cambios sumamente traumáticos a los ojos de cualquier observador. El 15 de agosto de 1908, Rafael Barrett publicó en El Diario (Asunción) el primero de los artículos titulados "Lo que son los yerbales". Su ofensiva contra las bases del llamado "progreso" paraguayo incluía toda una letanía de acusaciones escandalosas, entre ellas la siguiente:

"El Paraguay se despuebla; se le castra y se le extermina en las 7 u 8.000 leguas entregadas a la Compañía Industrial Paraguaya, a la Matte Larangeira y a los arrendatarios y propietarios del Alto Paraná. La explotación de la yerba mate descansa en la esclavitud, el tormento y el asesinato" $" 7$.

La campaña periodística de Barrett tropezaría con el fuerte rechazo de Manuel Domínguez y otros intelectuales nacionalistas de la Generación del 900, pero el anarquista cántabro tenía razón sobre las condiciones infrahumanas que muchos obreros tenían que soportar. La huida de peones era un problema frecuente para las empresas yerbateras. Por ejemplo, el 26 de mayo 1899, el presidente interino de la

\footnotetext{
${ }^{63}$ DALLA-CORTE CABALLERO, Gabriela. La Guerra del Chaco. Ciudadanía, Estado y Nación en el siglo XX. La crónica fotográfica de Carlos de Sanctis. Rosario: Prohistoria Ediciones, 2010, p. 144.

${ }_{64}$ ABENTE HAEDO, Víctor. El tribunal militar y la rebelión. Asunción: Talleres Nacionales de H. Kraus, 1903, p. 3.

${ }^{65}$ El comercio paraguayo. Op. cit., p. 138.

${ }^{66}$ MONTE DOMECQ, Ramón. La República del Paraguay... Op. cit., p. 351.

${ }^{67}$ BARRETT, Rafael. El dolor paraguayo y Lo que son los yerbales. Buenos Aires: Capital Intelectual, 2010, p. 125.
} 
Industrial Paraguaya, el asturiano Francisco G. Villamil, remitía al Ministerio de Relaciones Exteriores una lista de 198 fugitivos quejándose de la "facilidad que encuentran los peones contratados para sus explotaciones, de traspasar la frontera del Brasil [...] [y] perpetuar el verdadero despojo de que somos víctimas por ese concepto"68.

La alta movilidad de los campesinos desposeídos redundaba además en imparables flujos migratorios hacia los países vecinos y también desde la periferia hasta la zona urbana de Asunción y sus alrededores. Es probable que el mismo proceso se repitiera a escala reducida a medida que algunos de estos nuevos migrantes se dirigían a los incipientes centros comerciales e industriales de Concepción, Encarnación, Pilar y Villarrica. En consecuencia, a finales del siglo, los empresarios sacaban provecho de la recuperación económica, de la consolidación del liberalismo en Paraguay y en el Río de la Plata y, sin duda, de la proletarización del campesinado que había dado lugar a una mayor oferta de mano de obra.

Tal y como venimos exponiendo, este crecimiento económico favoreció también la llegada de inmigrantes procedentes del exterior y la consolidación de los negocios industriales y comerciales de quienes ya llevaban algún tiempo el país. Y entre ellos, se contaban algunos españoles. En Concepción, por ejemplo, uno de los dos aserraderos a vapor que entonces existían en la ciudad era el que el catalán Nicolás Fornells había fundado en 1892 que también contaba con taller mecánico, herrería y carpintería. De nuevo, carecemos de noticias sobre los primeros años del negocio, pero en 1911 López Decoud afirmaba que "ha venido progresando hasta el día de hoy, en que se encuentra montado á la moderna"69. Y como señal de esa modernidad reproducía en las páginas de su álbum una fotografía del motor utilizado en el aserradero, prueba fehaciente del alto nivel tecnológico y de la eficiencia industrial que Fornells introdujo en el mercado concepcionero. Por su parte, Báez hace hincapié en la impresionante escala de producción del catalán, cuyos talleres cubrían la extensión de una manzana entera y en ellos trabajaban "de 80 a 100 operarios ocupados en la construcción de carros, carretas, alza-primas, coches, vaporcitos y lanchas, y todo trabajo de mecánica y herrería"70. En los escuetos detalles biográficos que estos autores proporcionan, Concepción aparece como un destino secundario de Fornells. Habiendo llegado al Paraguay en 1885, durante los primeros años el catalán trabajó como mecánico en "el conocido establecimiento de Rusconi”, sobre el cual no hemos obtenido más datos pero que, casi con seguridad, no estaba asentado en Concepción ${ }^{71}$.

Como en el caso de Fornells, fue bastante común que los inmigrantes trabajasen para otros como paso previo al inicio de sus propios negocios. Los uruguayos Tomás y Rolando Herrero, por ejemplo, abrieron su casa de importaciones y exportaciones en Concepción en 1891. El local tenía instalados "un salón-despacho de 6 varas de

\footnotetext{
68 Archivo del Ministerio de Relaciones Exteriores del Paraguay. Departamento de Asuntos Consulares y Legalización, DACyL 54.

${ }^{69}$ LÓPEZ DECOUD, Arsenio (coord.). Álbum gráfico de la República del Paraguay. Asunción: Talleres Gráficos de la Compañía General de Fósforos, 1911, p. 115.

${ }^{70}$ BÁEZ, Cecilio. El Paraguay moderno. Op. cit., p. 353.

${ }^{71}$ lbídem.
} 
ancho por 10 de largo, varios depósitos para almacenar mercadería y un galpónbarraca para frutos del país", y el gerente y contador era "Don Vicente Campaya, de nacionalidad española [...] teniendo á sus órdenes 3 dependientes y 2 peones"72. El caso de Campaya como persona de confianza ostentando un puesto de responsabilidad no debió ser el único a tenor de algunas noticias publicadas en la prensa. El 19 de febrero 1892, el portugués Luis F. Braga publicó un aviso en un diario asunceno para participar "al comercio que el día 6 de Enero próximo pasado confirió poder general amplio al señor don Demetrio Rugel, para que le represente en todos sus asuntos y negocios"73. Con sus depósitos ubicados sobre la principal vía comercial de Asunción -la calle Palma-, Braga era "importador de "artículos de fantasía, tejidos de seda, de hilo, de algodón, muebles de Viena, artículos de bazar, lamparería y otros muchos, así como también algunos artículos [...] con el sólo y exclusivo fin de poder surtir á sus clientes del interior" ${ }^{\prime 74}$. Rugel llegó a ser un personaje de bastante prominencia en la comunidad española en Asunción, como evidencia el hecho de que fue nombrado vocal del Partido Republicano Español en la ya citada reunión de 1903. Pero, al igual que la mayoría de los inmigrantes españoles que hemos localizado en Concepción, desconocemos por qué mecanismo Rugel se trasladó más tarde a la Villa, aunque tal vez fuese a través de su contacto con la red de "clientes del interior" de la casa de Luis F. Braga.

Según el primer registro de los negocios existentes en la Villa publicado en El comercio paraguayo en $1898^{75}$ eran también españoles los propietarios de la única hojalatería, la de Ricardo Gómez y de una de las tres sastrerías, cuyo dueño era Ramón Lailla. Ambos se habían radicado en Concepción durante la década de los noventa ${ }^{76}$. También lo eran el regente de uno de los tres consultorios médicos existentes entonces en la Villa, así como del único estudio de pintura. Sobre este último, cuyo nombre era José María Hidalgo, al margen de la mención efectuada por Alvarenga Caballero acerca de una vista en óleo del puerto de Concepción que pintó en 1898 y que llegó a exhibirse en el Museo Cívico Municipal, no hemos podido hallar más información. Quizás pudiera aventurarse que en algún momento su negocio fracasó y se fue de Concepción.

Y es que el fin de siglo no fue un período propicio para el florecimiento de las artes plásticas en Paraguay, tal y como afirma Josefina Plá al evocar al paraguayo Saturio Ríos, que terminó quemando sus cuadros y yendo al campo para vivir como un ermitaño. La escritora canaria aseveraba que "el ambiente todavía pobre en experiencias valiosas en ese género, contagiado aún de conceptos peyorativos respecto al artista, identificaba a éste, amable y desdeñosamente, con el bohemio etc., etc. En otras palabras, la obra "consagrada" podía estimular; el artista en persona, inhibía"77. De las dificultades con las se podían encontrar los artistas da fe la experiencia del pintor gallego Joaquín Vaamonde Cornide, quien fue llevado desde Buenos Aires al Paraguay por su amigo Rafael Calzada cuando este viajó a

\footnotetext{
72 El comercio paraguayo. Op. cit., p. 488.

73 La Democracia (Asunción). 29 de febrero 1892, p. 2.

74 Ibídem, p. 487

75 lbídem, pp. 627-631.

76 lbídem, p. 630.

77 PLÁ, Josefina. Españoles en la cultura del Paraguay. Asunción: Araverá, 1985p. 120.
} 
Asunción para casarse con la paraguaya Celina González Peña en 1892. Y a pesar del deseo de Calzada de situarlo "en camino de hacer mucho dinero"78, las ambiciones de Vaamonde, descrito por Josefina Plá como el "único pintor de valía entre todos, españoles o no españoles, que nos visitó por esos años"79, no prosperaron. Falleció en 1900 en A Coruña, su ciudad natal.

\section{Expansión y modernización (1899-1932)}

Una de las nietas de Juan Cástulo Yáñez, un inmigrante procedente de Galicia que llegó al pueblo de Naranjaty durante la década de los veinte y contrajo matrimonio con la paraguaya Isidora Acosta, nos relató que su abuelo, además de ejercer como juez de paz, se dedicaba a trabajar en su huerta donde plantaba lechugas. A la hora de comer, los vecinos contemplaban asombrados la escena porque, para ellos, la lechuga era un alimento totalmente ajeno a su dieta. Era "comida de conejos" -decían- y se reían del gallego por comerla ${ }^{80}$. Esta anécdota apunta a uno de los efectos más sutiles de la inmigración, pues, los extranjeros llegaban con tradiciones gastronómicas distintas a las nativas. De hecho, para satisfacer el consumo de productos del Viejo Mundo a los que estaban acostumbrados los recién llegados, pero que también empezaban a ser demandados por los nacionales, surgió el denominado "comercio étnico". La mejor muestra del mismo en la capital concepcionera, fue el negocio de Constantino Ortiz, "España y América", cuyo nombre delataba el alcance internacional de su selección de productos ${ }^{81}$. El grado de conocimientos técnicos también resultaba importante. En 1902, por ejemplo, la propia la Corporación Municipal le compraba jabón al español Manuel Zorio ${ }^{82}$, dato que sirve una vez más como prueba de que la fabricación de algunos productos estaba monopolizada por inmigrantes.

El inmigrante gallego Cástulo Yáñez, al que acabamos de aludir, quien como juez de paz gozaba de cierto reconocimiento en Naranjaty, también formaba parte del proceso de repoblación -casi diríamos de recolonización- del interior del área concepcionera a principios del siglo XX. La guerra había deshecho gran parte de las transformaciones sufridas en esta zona fronteriza durante el siglo anterior, devolviéndola a la naturaleza y a los pueblos originarios. "Ya llegó" -relataba El Pueblo en noviembre de 1870, evocando aquella situación- "la espedición armada que el Gobierno mandó á la Concepción, para prevenir las invasiones de los indios" ${ }^{\prime \prime 3}$. Sin embargo, cuarenta años después, en los cañaverales entre la desembocadura del Ypané y los suburbios de Concepción ${ }^{84}$, el ingenio azucarero "La Caída", propiedad de Aurelio S. Agüero empleaba a 150 indígenas con un sueldo de

\footnotetext{
${ }^{78}$ CALZADA, Rafael. Cincuenta años de América. Notas autobiográficas. Buenos Aires: Librería y Casa Editora de Jesús Menéndez, 1927 (2 vols.), pp. 480-481.

${ }^{79}$ PLÁ, Josefina. Españoles en la cultura... Op. cit., p. 121.

${ }^{80}$ Agradezco a Mirta Yáñez López la información sobre su abuelo.

${ }^{81}$ CHAVES, Manuel W. El Paraguay ilustrado. Asunción: Talleres Gráficos de L.J. Ross y Cía., 1918, p. 249.

82 CCCC. Facturas de la Municipalidad de Concepción en la carpeta "Residentes españoles. Acción cultural, vida social y afines. Año: 1872-"

${ }^{83}$ El Pueblo (Asunción). 3 de noviembre 1870, p. 2.

${ }^{84}$ CHAVES, Manuel W. El Paraguay ilustrado. Op. cit., p. 246.
} 
cien pesos mensuales y comida incluida ${ }^{85}$.

Todas estas interacciones que, como se ha visto, pueden incluso rayar en lo anecdótico, dan buena cuenta de los profundos cambios provocados con el advenimiento del siglo XX derivados del proceso modernizador y (re)colonial en Concepción.

En la ciudad, y hasta cierto punto también en el campo, los españoles desempeñaron un papel destacado en muchas de estas transformaciones. En el ámbito urbano, por ejemplo, entre 1898 y 1913, cuando Genaro Romero visitó la ciudad, el número de comercios había aumentado notablemente y los españoles todavía se agrupaban en algunos sectores concretos. En esa etapa, dos de los cuatro depósitos de mercaderías; una de las dos canchas de bochas; la única confitería; una de las cuatro droguerías; uno de los tres aserraderos a vapor; una de las tres barracas de cuero; una de las dos colchonerías; uno de los dos comisionistas; uno de los dos talleres de curtiembre; la única fábrica de carros; una de las tres hojalaterías; una de las dos jabonerías; una de las cuatro panaderías y una de las cuatro talabarterías y zapaterías estaban administrados por españoles ${ }^{86}$.

Parte de la modernización pasaba por convertir al Paraguay en un país agroexportador por lo que era necesario disponer de mejores infraestructuras. Un paso importante fue la construcción de una aduana para reemplazar el muelle de Carísimo y Larangeira. En 1874 solo dos vapores brasileños y una flota de goletas italianas servían todo el río Paraguay ${ }^{87}$. Pero el tráfico fluvial aumentaba, el tamaño de las embarcaciones también, y para 1904 había tres agencias marítimas en Concepción: Bisso y Sosa, Adolfo Bourgoing, y Basilio Quevedo y Cía ${ }^{88}$. En 1916 se importaron 1.722.638 kilos de mercaderías por la aduana de Concepción: nada que ver con los 81.418.291 kilos que pasaron por la de Asunción y algo menos de los 1.974.791 de Encarnación, pero más que las importaciones que entraron por la aduana de Pilar de Ñeembucú (468.379 kilos), Humaitá (232.660) y Ayolas (179.745). Concepción también era el tercer puerto para las exportaciones. En el mismo año, las tarifas cobradas por exportaciones en la aduana de Asunción alcanzaban los 3.565.272 pesos oro sellado, 689.037 en Encarnación, 205.481 en Concepción, 172.204 en Pilar, 134.809 en Villeta, 75.085 en Humaitá y 18.700 en Ayolas $^{89}$. La diferencia exagerada entre Encarnación y Concepción se explica por el hecho de que esta competía con la Colonia Risso, Puerto Max, Puerto Casado, Puerto Pedernal y otros a cargo de grandes empresas agropecuarias, mientras que Encarnación era el único puerto importante en su zona de influencia, salvo Carmen del Paraná.

El 13 de septiembre 1912, el gobierno de Eduardo Schaerer aprobó una inversión pública de $\$ 1.750 .000$ para la construcción de puertos y aduanas en Concepción, Encarnación y Villeta. El 11 de noviembre se formó una comisión

\footnotetext{
${ }^{85}$ ROMERO, Genaro. El Paraguay progresa... Op. cit., p. 32.

${ }^{86}$ ROMERO, Genaro. El Paraguay progresa... Op. cit., pp. 49-52.

87 JOHNSTON, Keith. Recent Journeys in Paraguay. Op. cit., p. 310.

${ }^{88}$ BERAUD, Carlos. Guía comercial... Op. cit., p. 257.

${ }^{89}$ República del Paraguay. Anuario estadístico, 1916. Asunción: Talleres Gráficos del Estado, 1917, pp. 10-11.
} 
gestora de obras en Concepción en la que despuntaba la presencia española. El presidente de la comisión era José Giménez, castellano de Ávila. El tesorero era Basilio Quevedo, vástago de una de las principales familias de la élite norteña, el secretario era Carlos Miranda, y los vocales eran Eduardo Cabrera, Emilio Sienra, José Romañach y Demetrio Rugel, siendo españoles estos últimos ${ }^{90}$. Algunos de ellos, como José Giménez -un "caracterizado y acaudalado comerciante, se encarga de la administración financiera de las obras con una actividad y escrupulosidad dignas de los mayores encomios" ${ }^{\prime 1}$-, tenían experiencia previa en la gestión de la administración local. En la misma línea, el español español Enrique Lailla -pariente del sastre Ramón Lailla que figuraba en El Comercio Paraguayo de 1898- dirigió una carta al presidente de la municipalidad, fechada en octubre 1907 con la que acusaba recibo:

"De su carta del día Octubre 30 del actual, en la que me comunica que con los Sres. [José] Giménez y [Nicolás] Fornells fui designado para examinar el estado higiénico seccional, del radio por $\mathrm{Vd}$. Indicado.

En contestación pues, me es grato participarle que acepto gustoso el cargo que tuvo ha bien [sic] nombrarme ${ }^{92, "}$.

Por su parte, en septiembre de 1908, el catalán José Romañach había llegado a ser designado presidente de la Corporación Municipal. Y a pesar de que se mostró muy agradecido por el nombramiento, se vio obligado a manifestar "la imposibilidad, de aceptar el cargo antedicho; motivos ocurridos en el seno de mi familia, y que son de su conocimiento no me permiten por ahora acompañarlos en tan noble labor, sin perjuicio de hacerlos más adelante" ${ }^{\prime \prime 3}$. Sin embargo, no está claro si en algún momento Romañach llegó a ejercer como presidente municipal, si bien en 1915 aparece como vocal suplente de la Honorable Junta Municipal compuesta por una mezcla de italianos y paraguayos: Héctor Franco (presidente), Abel Lima (vicepresidente), Basilio Quevedo y Antonio Paciello (vocales titulares), Adriano Semidei (vocal suplente), Teonilo Giménez (secretario) ${ }^{94}$. Pero lo que sí es seguro es que Romañach desempeñó un cargo de carácter diplomático a tenor del contenido del Decreto 778 del 9 de julio 1913 en el que el gobierno paraguayo daba cuenta de:

"La nota de la Legación de España, de fecha 2 de noviembre del corriente en la que [ilegible] el correspondiente exequatur para La Carta Patente que acredita al Sr. José Romañach y Sastre como Vice-Cónsul honorario de su país en la ciudad de Concepción, con jurisdicción en el departamento del mismo nombre ${ }^{95}$.

Este nombramiento se produjo cuando la industria catalana estaba en auge y el comercio barcelonés, notablemente el promovido por la Casa de América, una de las mayores instituciones hispano-americanistas de su época, procuraba nuevos

\footnotetext{
${ }^{90}$ ROMERO, Genaro. El Paraguay progresa... Op. cit., p. 26.

${ }^{91}$ Ibídem, p. 27.

${ }^{92}$ CCCC. Carta de Enrique Lailla al Presidente de la Corporación Municipal, 31 de octubre 1907.

${ }^{93}$ CCCC. Carta de José Romañach al Presidente de la Corporación Municipal, 1 de septiembre 1908.

${ }^{94}$ BÁEZ, Cecilio. El Paraguay moderno. Op. cit., p. 344.

${ }^{95}$ CCCC. Copia de Decreto 778.
} 
proveedores de materias primas ${ }^{96}$. Como Vice-Cónsul honorario, la misión de Romañach sería canalizar las exportaciones de maderas procedentes de los bosques de Concepción hacia España. Que se le confiase este cargo es una prueba de su prestigio en el comercio local y de su capacidad para articular una extensiva red de contactos profesionales.

A Romañach le sucedió en el cargo consular el doctor zamorano Santos Canillas y Hernández Helena, tal como recuerda una placa conmemorativa colgada actualmente en la fachada de su casa: "Médico-Cirujano-Partero. Benefactor de Concepción. Vice-Cónsul Honorario de España". Y no fue, por cierto, el único español que ejerció en Concepción tareas relacionadas con la sanidad, materia en la que, desde tiempo atrás, la contribución extranjera resultó fundamental porque en el Paraguay no existió una facultad de medicina hasta principios del siglo XX. La Universidad Nacional se inauguró en 1890 con tres facultades, pero las de Medicina y Matemáticas tuvieron una vida efímera de menos de dos años. Sobrevivió la de Derecho con el apoyo del rector, el abogado vasco Ramón Zubizarreta. Entonces, algunos de los inmigrantes más prestigiosos eran médicos. El escocés Guillermo Stewart, que sirvió bajo el gobierno de López en la Guerra Guazú, fue, sin duda, el más famoso. Una vez consolidada la Facultad de Medicina, la mayor parte de los profesores también procedieron del extranjero: italianos como Domingo Scavone, el francés Miguel Elnassian, y españoles como Manuel Fernández Sánchez, Serafín Rivas Rodríguez (gallegos), Juan Vallory i Corquiela, Flaviano García Rubio (catalanes), Juan Borrás y Pardo o Félix Diez Pérez ${ }^{97}$.

Sin duda, durante este período iniciado con el siglo $X X$, los galenos españoles dejaron su huella en Concepción, tal y como señala en 1911 Monte Domecq quien dedicaba una página de su álbum conmemorativo del centenario dedica al cuerpo médico de la ciudad. El cirujano Vicente Álvarez servía a la guarnición militar, mientras que los civiles podían acudir a los consultorios de Lázaro B. Toranzos "consultorio concurridísimo"- y Manuel P. de Lafuente:

"El distinguido facultativo español doctor Lafuente está radicado en Concepción desde hace largos años [ya figura en El Comercio Paraguayo de 1898]. Culto e ilustrado, el doctor Lafuente goza de grandes simpatías en la sociedad concepcionera, en la que tiene una vasta clientela. Como operador ha demostrado en reiteradas ocasiones su competencia en operaciones de alta cirugía. Es digno de mención su desinterés para con los pobres, á quienes atiende con solicitud, por lo que goza de justo y renombrado prestigio, no solamente en Concepción, sino también en los principales pueblos del Norte. El doctor Lafuente, y su distinguida familia, ocupan un rango prominente en la culta sociedad de Concepción"98.

Por esos años, la asistencia pública consistía en un médico municipal (en 1915 sería Vicente Álvarez ${ }^{99}$ ) y dos parteras diplomadas, más un presupuesto mensual de 1.000 pesos para proveer a los pobres de medicamentos. Una farmacia distinta se encargaba de repartirlos todos los meses. El número de habitantes de la "ciudad" ya

\footnotetext{
${ }_{96}^{96}$ CAGIAO VILA, Pilar y DALLA-CORTE, Gabriela. La Casa de América de Barcelona... Op. cit., p. 7.

${ }_{97}^{9}$ PLÁ, Josefina. Españoles en la cultura... Op. cit., p. 126.

${ }^{98}$ MONTE DOMECQ, Ramón. La República del Paraguay... Op. cit., p. 319.

${ }^{99}$ BÁEZ, Cecilio. El Paraguay moderno. Op. cit., p. 344.
} 
alcanzaba los 14.000 , lejos de los 600 de la "villa" de 1874. No obstante, según Genaro Romero, "a pesar de los medios deficientísimos de que dispone la Municipalidad, el estado sanitario de la población ha mejorado"100. Entrada ya la década de los veinte, el director del Hospital Regional sería el doctor Santos Canillas y Hernández Helena, mencionado más arriba. Una carta suya fechada en 1927 deja ver que la falta de medios seguía siendo un problema, dado que Santos Canillas tenía que solicitar "un pequeño lote de elementos de cirujía que serían de gran utilidad para nuestra institución". El 27 de julio se lo concedió el Honorable Consejo Deliberante, a cargo del intendente, Cayo Aquino Quevedo, y el presidente municipal, Alberto Closa, hijo de aquel zapatero que, como se dijo párrafos atrás, había fundado en 1885 la célebre talabartería "La Concepcionera"101.

En otro orden de cosas más relacionadas con trasvases de tipo cultural, tanto Báez como Chaves reproducen en sus obras distintas fotografías del Palacio de la Intendencia, representativo de la transición arquitectónica que tuvo lugar entre el hispanismo colonial -construcciones como el cuartel rodeadas de "corredor jere"- y la corriente italianizante "impuesta en Concepción por los valencianos José Chust Gallegos y José Chust Martínez, y que se inscribe dentro del modernismo finisecular del siglo XIX"102. Más allá de los edificios públicos, esta corriente determinaba las formas arquitectónicas de las nuevas viviendas y negocios de los adinerados comerciantes. Tal fue el caso de Francisco Closa y sus hijos, quienes "respondiendo a una mayor amplitud de sus negocios, han mandado construir un palacete con las comodidades necesarias para instalar todas las dependencias de la casa comercial" ${ }^{103}$. En este sentido, cabe señalar que la fábrica de fideos "La Española" de los Lailla-Bardají era una edificación singular. La calle de la Aduana, donde esta familia española instaló su tienda de estilo Art Decó, era la vía comercial más importante de la ciudad. Popularmente conocida como la "calle del Tinglado", exhibía una selección ecléctica de formas arquitectónicas: las casas coloniales de la aristocracia concepcionera (como la mansión de Cayo Aquino Quevedo), el estilo neoclásico de la casa de Waldemar López, o el renacentismo de la Villa "Ida" de los Albertini ${ }^{104}$.

La innovación estilística y el diseño de viviendas cada vez más lujosas se repetía en otras localidades del país, como en las "casas del 900" de Areguá. Esta tendencia tenía la función de permitir que los más ricos hicieran una muestra pública de su éxito, entendido como síntoma de sus cualidades morales, es decir la honradez e inteligencia que teóricamente podían abrirles las puertas de la alta sociedad a cualquiera que supiera trabajar y ahorrar. De este modo, con sus amplios salones y muebles europeos, podían disfrutar de un nivel de confort que la humilde y tradicional casa "kuláta jovái" (dos pequeñas piezas con un pasillo abierto al aire libre entre ellas) no permitía, aunque se adaptase mejor al clima paraguayo. Además, se vivía una época en que "europeizar" y "modernizar" eran prácticamente sinónimos. Este fue el motivo de las disposiciones oficiales que, por ejemplo,

\footnotetext{
${ }^{100}$ ROMERO, Genaro. El Paraguay progresa... Op. cit., pp. 10-11.

${ }^{101}$ CCCC. Carta de Santos Canillas al Intendente Municipal, 1927 s/f.

${ }^{102}$ CCCC. "Datos sobre Concepción", informe inédito de Pedro A. Alvarenga Caballero, 1985.

${ }^{103}$ CHAVES, Manuel W. El Paraguay ilustrado. Op. cit., p. 230.

${ }^{104}$ CCCC. "Datos sobre Concepción", informe inédito de Pedro A. Alvarenga Caballero, 1985.
} 
pretendían prohibir las vaporosas vestimentas blancas que solían llevar las mujeres paraguayas, o los ponchos para los hombres ${ }^{105}$. En este clima cultural, en el que los detentores del poder político y económico eran tan proclives a absorber e imitar lo europeo, la modernización arquitectónica se veía como una señal de modernización.

El reflejo de Europa también se dejó sentir en el ámbito educativo. La privatización masiva había tenido el efecto positivo de generar un grado de liquidez que posibilitó proyectos como la Universidad Nacional de Asunción o los Colegios Nacionales de Concepción, Encarnación y Villarrica, aprobados por una Ley de 1889 ${ }^{106}$. Es oportuno añadir que el primer director del Colegio Nacional concepcionero fue el español Enrique Domínguez y Rodríguez Pelayo ${ }^{107}$. Este hecho es una manifestación local de lo que Amaral denomina la "parábola hispánica", ese lapso de aproximadamente treinta años durante los cuales la acción cultural de los peninsulares fue realmente notable ${ }^{108}$. En las rotativas, en las aulas, en las conferencias y lecturas poéticas del Ateneo Paraguayo, o en el escenario del Teatro Nacional, los españoles asumieron un papel central en la vida artística de la posguerra y la formación intelectual de los pensadores paraguayos de la generación posterior.

Sin embargo, las reformas educativas de las siguientes décadas non impidieron que las familias más pudientes mandasen a sus hijos a estudiar fuera de Concepción. Víctor Abente Haedo (n.1882) se educó en el Colegio Nacional de Asunción ${ }^{109}$. El catalán Nicolás Fornells envió a Europa a sus hijos, Emiliano y Fernando, para ampliar su formación ${ }^{110}$. Y, todavía en 1927, la comisión directiva de la recién fundada Escuela de Comercio "Basilio Quevedo" declaraba que Concepción seguía careciendo de suficientes vías de educación secundaria y superior:

"Nuestra juventud, en general sin contacto con los centros de estudios profesionales, secundarios y superiores del país, a los 15 años más o menos, cierra obligadamente los ojos a toda visión cultural ulterior. Decepcionados entonces, y casi sin fe y sin rumbo, pero con la conciencia clara de su situación frente al porvenir, se incorpora afanosamente a los gremios, en procura, no precisamente de medio de vida, sino de conocimientos profesionales, que solo pueden adquirir escasa e incompletamente ${ }^{111 "}$.

El 26 de agosto del mismo año, Francisco Ocariz (nieto de Guillermo) envió una carta desde Berlín, donde estudiaba derecho, a su tío José Bañuelos en Concepción. En ella, Ocariz expresaba su pesimismo acerca de los horizontes culturales de la juventud paraguaya:

\footnotetext{
${ }^{105}$ CARDOZO, Efraím. Apuntes de historia cultural del Paraguay. Asunción: Servilibro, 2007, pp. $301-$ 302.

${ }^{106}$ CENTURIÓN, Carlos R. Historia de las letras paraguayas. Op. cit., p. 93.

${ }^{107}$ ALVARENGA CABALLERO, Pedro A. Villa Real de Concepción... Op. cit., p. 64.

${ }^{108}$ AMARAL, Raúl. Viriato Díaz-Pérez y la Generación del Novecientos. En: DíAZ-PÉREZ, Viriato. Literatura del Paraguay. Vol. I. Movimiento intelectual. Palma de Mallorca: L. Ripoll, 1980 (2 vols.), p. 11.

${ }^{109}$ CENTURIÓN, Carlos R. Historia de las letras paraguayas. Op. cit., p. 213.

${ }^{110}$ MONTE DOMECQ, Ramón. La República del Paraguay... Op. cit., p. 202.

${ }^{111}$ CCCC. Carta C.D. Escuela de Comercio "Basilio Quevedo” a Sucesión Ocariz, abril 1927.
} 


\begin{abstract}
"Por lo menos en mi estadía en esta quisiera ver todo lo que me fuera posible, pues esta oportunidad es única para mí y si no la aprovecho sería muy tonto. En esa ya sabes muy bien la vida de todos nosotros, paraguayos que no tenemos ni idea de la vida y cualquier abogacillo se cree una potencia en sabiduría, y son más tontos que mandados hacer. Hace poco estuvo por acá unos de célebres [sic] (como hay tantos en Asunción) abogados a visitar Berlín y lo encontré con tantas tonterías que no tuve ganas de sacarlo para mostrarle algo de esta ${ }^{112 " . ~}$
\end{abstract}

En definitiva, aunque no hay que desestimar las mejoras producidas en el campo de la educación durante el período analizado, obviamente no alcanzó el nivel de calidad que se deseaba.

Concepción también experimentó mejoras en su infraestructura durante las primeras décadas del siglo pasado, sobre todo la construcción del Ferrocarril del Norte del Paraguay (1909-1915) de Guggiari, Gaona y Cía, cuyos esfuerzos, según Chaves, "han bastado para cambiar por completo el aspecto de gran parte de la zona por donde la trocha angosta ha llevado su obra de civilización y de progreso" 113 . Sin embargo, una evaluación actual del impacto del ferrocarril ha de efectuarse con mayores reservas. Las oportunidades que los trenes brindaban estaban limitadas por el pésimo estado de las carreteras, intransitables cuando llovía, y la casi inexistencia de caminos en las regiones selváticas, pues "la pérdida de hombres y mercancías en estos trayectos era considerada normal hasta bien entrado el siglo XX"114. O sea, el Ferrocarril del Norte del Paraguay aunque facilitaba el desarrollo agropecuario del interior de Concepción, quedaba limitado a las explotaciones de madera y yerba mate establecidas en un radio de varios kilómetros a cada lado del trazado de las vías.

En la actividad ganadera desarrollada en las estancias del interior, bastante más heterogénea que la implementada en el comercio yerbatero por la Industrial Paraguaya y la Matte Larangeira, las mayores empresas estaban financiadas por capital extranjero, especialmente anglo-argentino ${ }^{115}$. Pero también había considerables intereses españoles, como los representados en la Rural Española, propiedad del catalán Pedro Jorba. Jorba llegó a Asunción en 1874 con 19 años, llamado por su tío Juan Rius para trabajar en sus negocios junto con Francisco Rivas. La razón social Rius y Jorba S.A. se registró en $1882^{116}$. Y aunque la Rural Española una aventura económica secundaria para Jorba, su crecimiento fue posible precisamente gracias al capital obtenido como socio de la casa comercial más poderosa del país ${ }^{117}$. En 1918, Chaves efectuaba la siguiente observación sobre la Rural afirmando que:

"Hace un par de años, la Rural Española, cuando se hablaba de establecimiento ganadero, ocupaba un lugar secundario y cuando se enumeraban los primeros del

\footnotetext{
${ }_{112}^{112}$ CCCC. Carta de Francisco Ocariz a José Bañuelos, 26 de agosto 1927.

${ }_{113}$ CHAVES, Manuel W. El Paraguay ilustrado. Op. cit., p. 251.

114 RIVAROLA, Milda. Obreros, utopías \& revoluciones. Formación de las clases trabajadoras en el Paraguay liberal (1870-1931). Asunción: Servilibro, 2010, pp. 52-53.

115 Ibídem, p. 116.

${ }_{116}^{116}$ El comercio paraguayo. Op. cit., pp. 10-11.

${ }^{117}$ MORALES RAYA, Eva. La emigración catalana... Op. cit., pp. 404-405.
} 
país, no se la recordaba. Hoy, por la calidad de razas y por la cantidad de animales finos de pura sangre que ha importado, es, como hemos manifestado, el más valioso establecimiento ganadero del Paraguay ${ }^{118 " .}$.

Carlos Jorba fue el gerente de la Rural Española y sus 24 leguas (45.000 hectáreas) de tierras, organizadas en las tres estancias Belén-cué, Caapucumí y Desaguadero, y los tres puertos habilitados sobre el río Paraguay para sus operaciones en la zona de Concepción. Jorba recorría este enorme latifundio en un automóvil Ford, sin duda uno de los primeros vehículos de este tipo en el contorno $^{119}$. Su principal mérito, al juicio de Chaves, consistió en la labor de cruce de vacas criollas -descendientes del plantel correntino que repobló el campo durante la década de 1870-con razas importadas. En 1904, el secretario de la Sociedad Ganadera del Paraguay, Narciso M. Acuña, escribía que "estoy convencido de que esos criollos del Paraguay son algo muy especial [...] aptos para apropiarse las buenas cualidades de las razas superiores" mediante el cruce ${ }^{120}$. Con el objetivo de conseguir tal perfeccionamiento, Jorba importó la raza Polled Angus desde Entre Ríos. Este experimento de cruce representaba una enorme inversión y un altísimo nivel de riesgo que solo una empresa grande como la Rural Española podría asumir. Según Chaves:

Hace apenas unos meses vimos desembarcar en Remanso Castillo el plantel más grande de animales finos que haya llegado del exterior al Paraguay; ese plantel se componía de más de trescientas piezas de Polled Angus de pura sangre y más de doce toros de pedigree. El importe del block de esta hacienda, con los gastos de transporte, cuidados que han requerido para llegar en perfecto estado, como se encuentran ahora en la Rural Española, calculamos en cien mil pesos oro, que no es una suma despreciable, cuando se trata de ensayos de esta naturaleza.

[...] ¡Qué espectáculo consolador se ofrecía a la vista al admirar la importación de esos animales de raza, que constituye la importación de nueva vida, más vigorosa, más robusta, que, al correr de muy pocos años ha de transformar nuestra industria madre, nuestra riqueza ganadera, la única verdadera y positiva en el Paraguay! ${ }^{121}$

Otro estanciero español importante fue Guillermo Ocariz. Después de haber trabajado en los yerbales, con su antiguo patrón, el uruguayo Nicolás Otaño, formó una sociedad de compraventa de ganado y caballos. Cinco años después, ya en posesión un buen capital, Ocariz pudo comprar su propia estancia, Recalde-cué, a la que añadió la estancia Loma. A la altura de 1911 estas dos propiedades reunían un total de 8.000 vacas (solo seis de los 69 propietarios de la zona contaban con más animales). Según Monte Domecq, Ocariz también realizaba experimentos de cruce:

"Como hacendado competente su preocupación constante ha sido la mestización, comprendiendo que en ello está el porvenir de la ganadería, porque evita la degeneración progresiva de la raza criolla, muy estimable por su cuero, pero de

\footnotetext{
${ }^{118}$ CHAVES, Manuel W. El Paraguay ilustrado. Op. cit., pp. 225-236.

119 Ibídem, p. 237.

120 ACUÑA, Narciso M. La ganadería en el Paraguay. Asunción: Talleres Nacionales de H. Kraus, 1904, p. 17.

${ }^{121}$ CHAVES, Manuel W. El Paraguay ilustrado. Op. cit., p. 239.
} 
ínfimo peso, de carne escasa y poca grasitud, que la hace inapropiada para la explotación moderna en frigoríficos y sólo sirve para su transformación en tasajo ó en carne salada, ó para la fabricación de extracto de carne ${ }^{122 ", . ~}$

Los hijos de Guillermo Ocariz, Gaspar, Sixto y Agustín, también se dedicaban a la ganadería, y su hija, Teresa Ocariz, estaba casada con otro ganadero español: el riojano José Bañuelos. Bañuelos colaboraba con sus cuñados en la compraventa de animales, aunque no tenemos constancia de cuántos animales tenía ni cuál era la superficie de su propiedad ${ }^{123}$.

Por otro lado, en el censo de ganadería de Concepción del año 1926, los gallegos Victoriano y Victorino Abente y Lago aparecen como los dueños respectivos de las estancias de Santa Inés de la Sierra y Garay-cué, en el Partido de Concepción. La primera medía unas 26.250 hectáreas con 6.530 cabezas de ganado, mientras que Garay-cué medía 12.656 hectáreas y tenía 2.634 animales. Victorino Abente nunca vivió en Concepción, por lo cual Victoriano probablemente se encargase de la gestión de las estancias de su hermano. La Tabla 1 resume la distribución de los establecimientos declarados por hectáreas en el Partido de Concepción, uno de los diez Partidos de la zona de Concepción.

\begin{tabular}{|c|c|c|}
\hline \multicolumn{2}{|c|}{$\begin{array}{c}\text { Distribución de los establecimientos declarados por hectáreas en el Partido de } \\
\text { Concepción }\end{array}$} \\
\hline $\begin{array}{c}\text { Establecimientos declarados por } \\
\text { hectáreas }\end{array}$ & $\begin{array}{c}\text { Partido de } \\
\text { Concepción }\end{array}$ & $\begin{array}{c}\text { Zona de } \\
\text { Concepción }\end{array}$ \\
\hline $1-50$ & 3 & 10 \\
\hline $51-250$ & - & 14 \\
\hline $251-500$ & 1 & 6 \\
\hline $501-1.000$ & 3 & 9 \\
\hline $1.001-2.000$ & 5 & 33 \\
\hline $2.001-5.000$ & 8 & 23 \\
\hline $5.001-10.000$ & 16 & 29 \\
\hline $10.001-20.000$ & 12 & 24 \\
\hline$>20.000$ & 16 & 27 \\
\hline Total & 64 & 185 \\
\hline
\end{tabular}

Tabla 1: Distribución de los establecimientos declarados por hectáreas en el Partido de Concepción. Fuente: Elaboración propia a partir de CCCC. Censo de ganadería de la zona de Concepción, 1926.

Una docena de los 64 establecimientos en el Partido (18,75\%) y 24 de los 185 establecimientos de la zona de Concepción (12,79\%) declaraban una superficie de 10.001-20.000 hectáreas. Para los establecimientos de más de 20.000 hectáreas, las cifras son de 16/64 (25\%) y 27/185 (14,59\%). Por eso, las propiedades de los Abente, sobre todo la de Victoriano, se contaban entre las mayores de Concepción aunque no eran excepcionales en su Partido, donde solo 20 de los 64 establecimientos $(31,25 \%)$ medían 5.000 hectáreas o menos (aunque se supone que habría bastantes pequeñas explotaciones que no se declararon). En cambio, en toda la zona de Concepción, las estancias de 5.000 hectáreas o menos eran más

\footnotetext{
122 MONTE DOMECQ, Ramón. La República del Paraguay... Op. cit., p. 351.

${ }^{123}$ CCCC. Telegramas de Sixto Ocariz a José Bañuelos, 12 y 18 de mayo 1927.
} 
numerosas: 95 de las 185 declaradas (51,35\%). Esto apunta a diferencias en la división de la propiedad y en la intensidad de pastoreo en los distintos Partidos, tal como se observa en la Tabla 2.

\begin{tabular}{|c|c|c|c|}
\hline \multicolumn{4}{|c|}{ Diferencias en la división de la propiedad y en la intensidad de pastoreo en los } \\
distintos Partidos \\
\hline Partido & $\begin{array}{c}\text { Superficie declarada } \\
\text { (hectáreas) }\end{array}$ & $\begin{array}{c}\text { Cabezas de ganado } \\
\text { declaradas }\end{array}$ & $\begin{array}{c}\text { Cabezas de } \\
\text { ganado/hectárea }\end{array}$ \\
\hline Concepción & 1.090 .572 & 362.774 & 0,33 \\
\hline $\begin{array}{c}\text { Villa de San } \\
\text { Pedro }\end{array}$ & 293.531 & 46.804 & 0,16 \\
\hline Bella Vista & 212.982 & 61.789 & 0,29 \\
\hline $\begin{array}{c}\text { Pedro Juan } \\
\text { Caballero }\end{array}$ & 183.375 & 2.544 & 0,01 \\
\hline Horqueta & 121.678 & 9.340 & 0,08 \\
\hline Lima & 58.916 & 7.409 & 0,13 \\
\hline Capitán Bado & 35,625 & 2.583 & 0,07 \\
\hline Loreto & 34.726 & 10.813 & 0,31 \\
\hline Tacuatí & 8.801 & 1.616 & 0,18 \\
\hline Belén & 2.792 & 865 & 0,31 \\
\hline Total & 2.042 .998 & 506.537 & 0,25 \\
\hline
\end{tabular}

Tabla 2: Diferencias en la división de la propiedad y en la intensidad de pastoreo en los distintos Partidos. Fuente: Elaboración propia a partir de CCCC. Censo de ganadería de la zona de Concepción, 1926.

A tenor de los datos expuestos, Concepción era el principal Partido ganadero de la zona. Representaba el $53,38 \%$ de la superficie declarada para la ganadería, el $71,62 \%$ de los animales registrados y tenía la mayor intensidad de pastoreo: 0,33 cabezas de ganado por hectárea. Esto se debe en parte a la dirección de la colonización agrícola -desde la ciudad de Concepción hacia Pedro Juan Caballero y Capitán Bado en el este- y en parte a la relativa preponderancia de las explotaciones yerbateras o madereras en distintos Partidos. La Industrial Paraguaya, por ejemplo, estaba concentrada en el oriente, lejos de las principales villas. Esto explica la poca superficie destinada a la ganadería en el Partido de Capitán Bado.

Otra de las facetas de la modernización fue la representada por la consolidación de nuevos tipos de agrupaciones cívicas en la que los inmigrantes fueron el motor de muchos de los cambios que se produjeron en ese ámbito. Las primeras asociaciones profesionales en el Río de la Plata fueron las de socorros mutuos, cuya aparición a finales del siglo XIX fue posterior a las asociaciones étnicas que, en algunos casos, también fueron concebidas como órganos de apoyo mutuo (los italianos, que como vimos llegaron a Concepción antes que los españoles, sí fundaron la sociedad étnica de socorros mutuos, denominada "Umberto l"). Estaban pensadas para proteger los intereses del patronal o los comerciantes autónomos, ya que sus cuotas de cuatro o cinco pesos mensuales non eran asequibles para los peones u obreros asalariados ${ }^{124}$.

${ }^{124}$ RIVAROLA, Milda. Obreros, utopías \& revoluciones. Op. cit., pp. 66-67. 
La Sociedad Artesanos de Socorros Mutuos se fundó en 1897. El 6 de mayo 1904, la comisión directiva apoderó a su presidente, el sastre español Ramón Lailla, "para hacer en su nombre todas las diligencias necesarias, para la adquisición de un lote de terreno baldío para edificar de acuerdo á la Ley, ante la Honorable Corporación Municipal”125. El 23 de marzo 1908, el presidente de la asociación, esta vez el hojalatero español Ricardo Gómez, dirigía una carta a la Corporación Municipal solicitando la "concesión gratuita del terreno que la Sociedad ha edificado, puesto que ha cumplido con las provisiones de la Ley y las ordenanzas municipales"126. El perito agrimensor municipal y vocal de obras públicas, Pedro Calabrese, examinó el caso y el 28 de marzo concluyó que "no existe ningún inconveniente de conceder la escritura de propiedad edificada"127. Pedro Calabrese aparece entre los miembros de la comisión directiva de la Sociedad Artesanos de Socorros Mutuos que Genaro Romero recoge para el año 1913 y representa un ejemplo nítido del vínculo entre la influencia política y el poder económico. De nuevo, en dicha nómina no está ausente la presencia española: Ricardo Gómez (presidente), Benjamín Colunga (vicepresidente), Teonilo Giménez (Secretario), Andrés Bonzi (tesorero), Ramón Lailla, Pedro Calabrese, Arturo Mariño, Coronado González, Ángel Giovine (docente en el Colegio Nacional), Luis Boselli (vocales), Luis Boselli (h) (porta estandarte), Francisco Closa (h), José Melgarejo (porta banderas), Ángel Giovine, Manuel Gómez (revisador de cuentas). Según Romero, la Sociedad "toma siempre participación en todas las festividades que se celebran en las fechas patrias nacionales y cada día aumenta el número de sus asociados porque atraen simpatías los propósitos humanitarios que constituyen el capítulo principal de su programa"128.

Si la Sociedad Artesanos de Socorros Mutuos cumplía una función económica, el Club Concepción representaba una nueva forma de sociabilidad. En 1912 o 1913 se nombró una comisión para proyectar un club social, el cual en principio se llamaría "La Recreativa". Los nombres de sus miembros ya son familiares: Basilio Quevedo, Carlos Miranda, Andrés Bonzi, Adriano Semidei, E. Pires. El vicepresidente era el español José Giménez ${ }^{129}$. El Club Concepción, la asociación de inauguró el 23 de agosto 1916 en la casa de Andrés Bonzi, "quien fue su primer Presidente [...] En 1925 por Decreto del Poder Ejecutivo, el Club Concepción adquiere personería Jurídica y ya se habla del local propio, en enero de 1931 se adquiere la compra del primer local propio"130. Las facturas de José Bañuelos (1927), firmadas por el tesorero G. González, muestran que los socios pagaban una cuota mensual de 50 pesos $^{131}$. El Club, entonces, era un lugar de sociabilidad reservado para las familias más acomodadas. En su microhistoria de Yaguarón, Toness profundiza en el significado histórico de los clubes sociales. En un plano ideológico, funcionaban como "misiones" de civilización europea, aunque el modelo más cercano era el de la oligarquía bonaerense. Compraban libros para escuelas, patrocinaban bailes y partidos de fútbol para sacar al joven paraguayo de los bares y

\footnotetext{
${ }^{125}$ CCCC. Carta de Ramón Lailla al Presidente de la Corporación Municipal, 5 de abril 1904.

${ }^{126}$ CCCC. Carta de Ricardo Gómez al Presidente de la Corporación Municipal, 23 de marzo 1908.

${ }_{127}$ CCCC. Informe de Pedro Calabrese al Presidente de la Corporación Municipal, 28 de marzo 1908.

${ }^{128}$ ROMERO, Genaro. El Paraguay progresa... Op. cit., pp. 22-25

129 Ibídem, p. 23.

130 Disponible en <http://www.clubconcepcion.org.py/>. [Consulta: 21 de agosto de 2019].

${ }^{131}$ CCCC. Facturas mensuales del Club Concepción para José Bañuelos, 1927.
} 
el salón de billares ${ }^{132}$. Los eventos que se realizaba en el Club tenían el carácter de espectáculos semipúblicos, celebrados en espacios exteriores por mor del clima cálido y la falta de un gran local. Así, a través de la ropa que vestían, sus gestos, los utensilios y muebles que utilizaban, los platos que comían y la música que se interpretaba, los socios diseminaban una imagen de "vida civilizada"133. En términos más amplios, los clubes encarnaban diferencias de clase:

"[...] la sociedad versus la gente, los que pertenecían al club social y los que no. Pertenecer al club social significaba que uno cumplía con los estándares generales de la sociedad (que uno estaba casado legalmente, que sus hijas no tenían malas reputaciones o hijos ilegítimos) y los requisitos económicos del grupo. Los requisitos económicos eran sencillamente que uno tenía que cumplir con los estándares suntuarios, tener suficiente dinero para el consumo conspicuo de comida y bebida, y reciprocar como anfitriones ${ }^{134 "}$.

José Bañuelos también contribuía una cuota de 50 pesos al Club Hípico Deportivo, cuya fecha de fundación se desconoce pero que habría complementado los propósitos sociales del Club Concepción con un itinerario recreativo ${ }^{135}$. Finalmente, en el ámbito de la cultura, tenemos noticias de la existencia de un Círculo Artístico Concepción. El nombre sugiere que el Círculo fomentaba el cultivo de las artes, pero el único documento que pudimos consultar se refiere a un fin humanitario. El 17 de julio 1922, el español Jesús Barrio Cajal, presidente de la asociación, envíaba una carta al Intendente para solicitar la licitación una rifa de 2.500 pesos ( 500 boletos a cinco pesos cada uno) para ayudar a las víctimas de la Guerra Civil (1922-1923). Una vez abonada la tasa correspondiente y con el visto bueno de los peritos Santos Canillas y Vicente Bayarri, ambos españoles, el Intendente les concedió el permiso para realizar dicha rifa y premiar al ganador con un busto de terracotta, una tricota de lana para caballero y una canasta de flores artificiales $^{136}$. En agosto la Intendencia licitó una segunda rifa del Círculo Artístico, esta vez de 2.000 pesos, con los siguientes premios: una vaca, una tricota para señora, un costurero y un par de anillos fantasía y lazos ${ }^{137}$. Con la excepción de la vaca, donada seguramente por un ganadero miembro del Círculo, todos estos premios eran objetos ornamentales vinculados a la "imagen de civilización" que la clase alta europea y europeizante quería imponer, lo cual no demerita el genuino altruismo que motivaba la rifa.

\section{Conclusión}

El presente estudio empieza a llenar una laguna en la historiografía paraguaya: la inmigración espontánea fuera de Asunción durante las décadas posteriores a la Guerra Guazú. Las pruebas aquí presentadas demuestran que, al igual que los probablemente más numerosos italianos, argentinos y brasileños, los inmigrantes españoles tuvieron una influencia cualitativa sobre las transformaciones que se

\footnotetext{
132 TONESS, Odin Alf. The Political and Social History... Op. cit., p. 84.

${ }^{133}$ Ibídem, p. 132.

134 Ibídem, pp. 130-131.

${ }^{135}$ CCCC. Facturas mensuales del Club Hípico Deportivo para José Bañuelos, 1928-1929.

${ }^{136}$ CCCC. Carta de Jesús Barrio Cajal al Intendente Municipal, 17 de julio 1922.

${ }^{137}$ CCCC. Carta de Jesús Barrio Cajal al Intendente Municipal, agosto 1922.
} 
produjeron en Concepción durante el período de entreguerras. En las investigaciones sobre un grupo étnico concreto, existe el riesgo de que, mediante la repetición de nombres y la exclusión de otros, surja una "ilusión óptica" que exagere la preponderancia de la nacionalidad estudiada. Por lo tanto, es de justicia clarificar que, por ejemplo, en la Intendencia Municipal de 1915, solo uno de los doce miembros, Vicente Lataza (procurador), era español, y el presidente era un alemán: Rodolfo Schreiber ${ }^{138}$.

Pero hemos comprobado la relevancia de este flujo migratorio peninsular, y no fue poca. La especialización de los inmigrantes hispanos en unos sectores comerciales particulares, como la hojalatería, la talabartería o el curtido de cueros, contribuyó a la recuperación económica de la posguerra y la penetración capitalista (con sus ventajas y desventajas). Los españoles también jugaron su papel en la diversificación económica posterior con la creación de nuevos tipos de negocios, como la fábrica de jabón de Manuel Zorio, la introducción de tecnologías industriales como el motor utilizado en el aserradero de Nicolás Fornells, de productos extranjeros -volvemos a mencionar las compras "Yanquis y Europeas" de Francisco Closa-, la expansión de la ganadería en grandes estancias como Santa Inés de la Sierra o Garay-cué, y la modernización de la misma a través de los experimentos de cruce de la Rural Española de Pedro Jorba.

Los nombres y lugares de origen recogidos insinúan que el mayor grupo de estos inmigrantes eran catalanes. Esto corrobora lo afirmado por Alvarenga Caballero y los cálculos de Morales Raya, la cual estima que lo era aproximadamente un tercio de los inmigrantes peninsulares en el Paraguay de entreguerras ${ }^{139}$. Entrando en el siglo XX, las fuentes consultadas permiten que el análisis se centre en otros cambios que afectaron la sociedad concepcionera. Mediante su participación en las direcciones de distintas administraciones públicas y asociativas, el impacto de los españoles se sentía en la alteración física de la ciudad (la modernización infraestructural y arquitectónica) y la esfera socio-cultural (la proyección de un estilo de vida europeo como aspiración ideal, por ejemplo en el Círculo Artístico Concepción).

Cuando, en 1933, muchos de los inmigrantes aquí citados se asociaron a la Legión Civil Extranjera, la cual es un tema pendiente en la historiografía de la Guerra del Chaco, el país a cuya defensa acudían ya no era lo que había sido en 1869 . Si las transformaciones sufridas desde 1869 eran constructivas o destructivas aún es un foco de debate, muchas veces menos histórico que ideológico. Pero si el Paraguay, y Concepción, habían cambiado, en parte fue gracias a la contribución de los inmigrantes españoles.

\section{Bibliografía}

ABENTE HAEDO, Víctor. El tribunal militar y la rebelión. Asunción: Talleres Nacionales de H. Kraus, 1903.

\footnotetext{
${ }^{138}$ BÁEZ, Cecilio. El Paraguay moderno. Op. cit., p. 344.

${ }^{139}$ MORALES RAYA, Eva. La emigración catalana... Op. cit., p. 443.
} 
ABENTE Y LAGO, Victorino. Antología poética, 1867-1926. Recopilación de Cándido Samaniego Abente. Asunción: Editora Litocolor, 1984.

ACUÑA, Narciso M. La ganadería en el Paraguay. Asunción: Talleres Nacionales de H. Kraus, 1904.

ALVARENGA CABALleRO, Pedro A. Villa Real de Concepción en los días de la ocupación brasileña. Historia Paraguaya. 1999, n. 39, pp. 49-94.

AMARAL, Raúl. Viriato Díaz-Pérez y la Generación del Novecientos. En: DíAZPÉREZ, Viriato. Literatura del Paraguay. Vol. I. Movimiento intelectual. Palma de Mallorca: L. Ripoll, 1980 (2 vols.).

ARECES, Nidia R. La política de tierras en Concepción, frontera norte paraguaya, durante el gobierno de Carlos A. López. Prohistoria. 1998, n. 2, pp. 93-106.

ARECES, Nidia R. Terror y violencia durante la Guerra del Paraguay: "La masacre de 1869" y las familias de Concepción. Revista Europea de Estudios Latinoamericanos y del Caribe. 2006, n. 81, pp. 43-63.

BÁEZ, Cecilio. El Paraguay moderno. Asunción: Talleres Nacionales de H. Kraus, 1915.

BARRETT, Rafael. El dolor paraguayo y Lo que son los yerbales. Buenos Aires: Capital Intelectual, 2010.

BENIITEZ MARTíNEZ, María Victoria. Inmigrantes europeos en Paraguay, 18181930. En: REY TRISTÁN, Eduardo y CALVO GONZÁLEZ, Patricia. 200 años de Iberoamérica (1810-2010). Actas del XIV Encuentro de Latinoamericanistas Españoles. Santiago de Compostela: Universidade de Santiago de Compostela, 2010, pp. 1099-1121.

BERAUD, Carlos. Guía comercial e industrial del Paraguay. Asunción: Carlos Beraud, 1904.

BOCCIA ROMAÑACH, Alfredo. La Villa de Pilar de Neembucú en la historiografía paraguaya desde su fundación hasta mediados del siglo XX. Asunción: Servilibro, 2007.

BRABO, Francisco Javier. Coleccion de documentos relativos á la expulsión de los Jesuitas de la República Argentina y del Paraguay, en el reinado de Cárlos III. Madrid: Est. Tip. De J.M. Pérez, 1872.

CABALLERO CAMPOS, Herib. Historia de las relaciones entre Paraguay y Gran Bretaña del siglo XVIII al siglo XXI. Asunción: Servilibro, 2017.

CAGIAO VILA, Pilar (ed.). Donde la política no alcanza. El reto de diplomáticos, cónsules y agentes culturales en la renovación de las relaciones entre España y 
América, 1880-1939. Madrid: Iberoamericana, 2018.

CAGIAO VILA, Pilar y DALLA-CORTE, Gabriela. La Casa de América de Barcelona y sus relaciones con Paraguay: comercio y diplomacia (1912-1922). En: NAVARRO, Consuelo y PRADO, Gustavo H. (coords.). Intellectualism and Migration: International Networks of European Culture (XIX-XXI). Rockville: GlobalSouth Press, 2016.

CALZADA, Rafael. Cincuenta años de América. Notas autobiográficas. Buenos Aires: Librería y Casa Editora de Jesús Menéndez, 1927 (2 vols.).

CARDOZO, Efraím. Apuntes de historia cultural del Paraguay. Asunción: Servilibro, 2007.

CENTURIÓN, Carlos R. Historia de las letras paraguayas. Vol. II. Buenos Aires: Editorial Asunción, 1948 (3 vols.).

CHAVES, Manuel W. El Paraguay ilustrado. Asunción: Talleres Gráficos de L.J. Ross y Cía., 1918.

DALLA-CORTE CABALLERO, Gabriela. La Guerra del Chaco. Ciudadanía, Estado y Nación en el siglo XX. La crónica fotográfica de Carlos de Sanctis. Rosario: Prohistoria Ediciones, 2010.

DALLA-CORTE CABALLERO, Gabriela. Mujeres, economía y sociedad de la República del Paraguay. Anuario de Historia. 2018, n. 30, pp. 194-216.

DALLA-CORTE CABALLERO, Gabriela. Relaciones hispano-paraguayas durante la Primera Guerra Mundial: el "Banco de España y Paraguay" en Asunción. Anuario de Estudios Americanos. 2016, n. 73, pp. 261-290.

DURÁN ESTRAGÓ, Margarita y ROMANO GARCÍA, Martín. Formación de la familia paraguaya. Asunción: Tiempo de Historia, 2011 (2 vols.).

El comercio paraguayo. 1898. (¿Asunción: Talleres Nacionales de H. Kraus?).

GAMARRA DOLDÁN, Pedro. Españoles ilustres en el Paraguay. Asunción: Prisa Ediciones, 2011.

GÓMEZ VÁZQUEZ, Melanio. Centro Español de Villarrica en el año de su centenario. Villarrica: Editorial Villa Rica, 2015.

JOHNSTON, Keith. Recent Journeys in Paraguay. The Geographical Magazine. 1875, 2.9-11, pp. 264-273, 308-313, 342-345.

LÓPEZ DECOUD, Arsenio (coord.). Álbum gráfico de la República del Paraguay. Asunción: Talleres Gráficos de la Compañía General de Fósforos, 1911. 
MONTE DOMECQ, Ramón. La República del Paraguay en su primer centenario, 1811-1911. Buenos Aires: Compañía Sudamericana de Billetes de Banco, 1911.

MORALES RAYA, Eva. La emigración catalana a Paraguay entre finales del siglo $X I X$ y principios del $X X$ : sociedad, cultura, política [tesis doctoral inédita]. Universitat de Barcelona, 2015.

PLÁ, Josefina. Españoles en la cultura del Paraguay. Asunción: Araverá, 1985.

POTTHAST, Barbara. Niños soldados y niñas famélicas. En: POTTHAST, Barbara y CARRERAS, Sandra (eds.). Entre la familia, la sociedad y el Estado. Niños y jóvenes en América Latina (siglos $X I X-X X$ ). Madrid: Iberoamericana Editorial Verveurt.

República del Paraguay. Anuario estadístico, 1916. Asunción: Talleres Gráficos del Estado, 1917.

RIVAROLA, Milda. Obreros, utopías \& revoluciones. Formación de las clases trabajadoras en el Paraguay liberal (1870-1931). Asunción: Servilibro, 2010.

RODRíGUEZ ALCALÁ, Javier. Notas sobre La Verdad Autógrafa de Plácido Casaús. De la imagen del poder al poder de las imágenes. Asunción: Ediciones Cabildo Bicentenario, 2011.

ROMERO, Genaro. El Paraguay progresa: la ciudad de Concepción. Asunción: Talleres Gráficos del Estado, 2013.

TEIJEIRO MARTÍNEZ, Benigno. El Paraguay: memoria bajo el punto de vista industrial y comercial en relación con los países del Plata. Buenos Aires: Establecemiento Tipográfico Calle de Perú no 107, 1882.

TONESS, Odin Alf. The Political and Social History of a Paraguayan Town [tesis doctoral]. University of Illinois, 1973.

WEBB, Philip Duncan. "Armados de noble ambición": os galegos en Paraguai e o seu lugar no ámbito asociativo español (1870-1932). Murguía: Revista Galega de Historia. 2016, n. 34, pp. 17-36.

ZUB KURYLOWICZ, Roberto. Tierra, trabajo y religión. Memoria de los inmigrantes eslavos en el Paraguay. Asunción: El Lector, 2002. 